\title{
Numerical and experimental analysis of a novel heat pump driven sorption storage heater
}

\author{
Devrim Aydin ${ }^{\mathrm{a}, *}$, Sean P. Casey ${ }^{\mathrm{b}}$, Xiangjie Chen $^{\mathrm{c}}$, Saffa Riffat ${ }^{\mathrm{c}}$ \\ a Department of Mechanical Engineering, Eastern Mediterranean University, G. Magosa, TRNC Mersin 10, Turkey \\ ${ }^{\mathrm{b}}$ The University Center, North Lindsey College, Scunthorpe DN17 1AJ, UK \\ ${ }^{\mathrm{c}}$ Architecture, Energy and Environment Research Group, Faculty of Engineering, University of Nottingham, University Park, Nottingham NG7 2RD, UK
}

\section{H I G H L I G H T S}

- A novel heat pump driven sorption storage heater system was investigated.

- System enables utilizing PV panels or off peak electricity tariff to store heat.

- Five different sorbents were investigated in the developed system.

- System provides an energy density of $170 \mathrm{kWh} / \mathrm{m}^{3}$ with the use of $\mathrm{V}-\mathrm{CaCl}_{2}$ as sorbent.

- Overall system heating COP was found 2.4 for long term operation ( $1200 \mathrm{mins})$.

\section{A R T I C L E I N F O}

\section{Keywords:}

SIM

Heat pump

Sorption heat storage

Composite adsorbent

Heating

Numerical and experimental analyses

\begin{abstract}
A B S T R A C T
This study investigates a hybrid "solid sorption heat storage/air sourced heat pump" system for energy efficient heating of buildings. The proposed system could convert excess energy generated using photovoltaic panels/offpeak electricity to heat and charge the sorption material to store that heat for later use. The novel heat recovery process employed in the system enables high heat storage efficiency through condensation of desorbed moisture in a heat storage charging cycle.

In this study five different sorbents were tested in a novel prototype system. Four sorbents were salt based composites (SIM's) and one was Zeolite 13X. According to the results, the coefficient of performance (COP) of the system varied in the range of 1-2 for short-term operation (where $t<240 \mathrm{~min}$ ) depending on the sorption material properties and system operating conditions. The overall performance of the prototype sorption storage heater was determined through long cycle testing. The system provided $\approx 6.8 \mathrm{kWh}$ thermal energy output with a sorbent volume, $V s=0.04 \mathrm{~m}^{3}$ (over a $1200 \mathrm{~min}$ discharge time), corresponding to an energy density, $E_{d}=170 \mathrm{kWh} / \mathrm{m}^{3}$. The required charging duration, to desorb the moisture was experimentally determined as $360 \mathrm{~min}$. Based on the total energy input-output for both charging and discharging processes, the $C O P_{S}$ was calculated at 2.39. According to the analysis, the experimental results were found in good agreement with the numerical simulation.
\end{abstract}

\section{Introduction}

In the building sector, a recast of the European Performance of Buildings Directive (EPBD2) is planned to enter into being by 2018, forcing all new buildings to become nearly net zero energy buildings (nZEB) [1]. The nZEB concept requires a high level of energy efficiency, in combination with on-site renewable energy use/production [2].

In this context, a vast amount of research has been performed on the development of new, efficient thermal energy storage (TES) technologies and materials to improve the utilization of solar air and water heating systems [3-5]. Technologies incorporating electrically sourced heating systems (i.e. heat pumps) with TES are also vital for improving energy efficiency in buildings. Although electricity is regarded as an expensive and inefficient way of producing heat, there is an emerging transition to solar and wind sourced 'on site' domestic electricity generation [6]. Due to the increasing trend in photovoltaic (PV) application, the storage of electricity is now being questioned. Current electrical energy storage technologies are expensive with research still ongoing. At today's battery prices, the point where the financial returns justify investment has not yet been reached [7]. However, without

\footnotetext{
* Corresponding author.

E-mail address: devrim.aydin@emu.edu.tr (D. Aydin).
} 


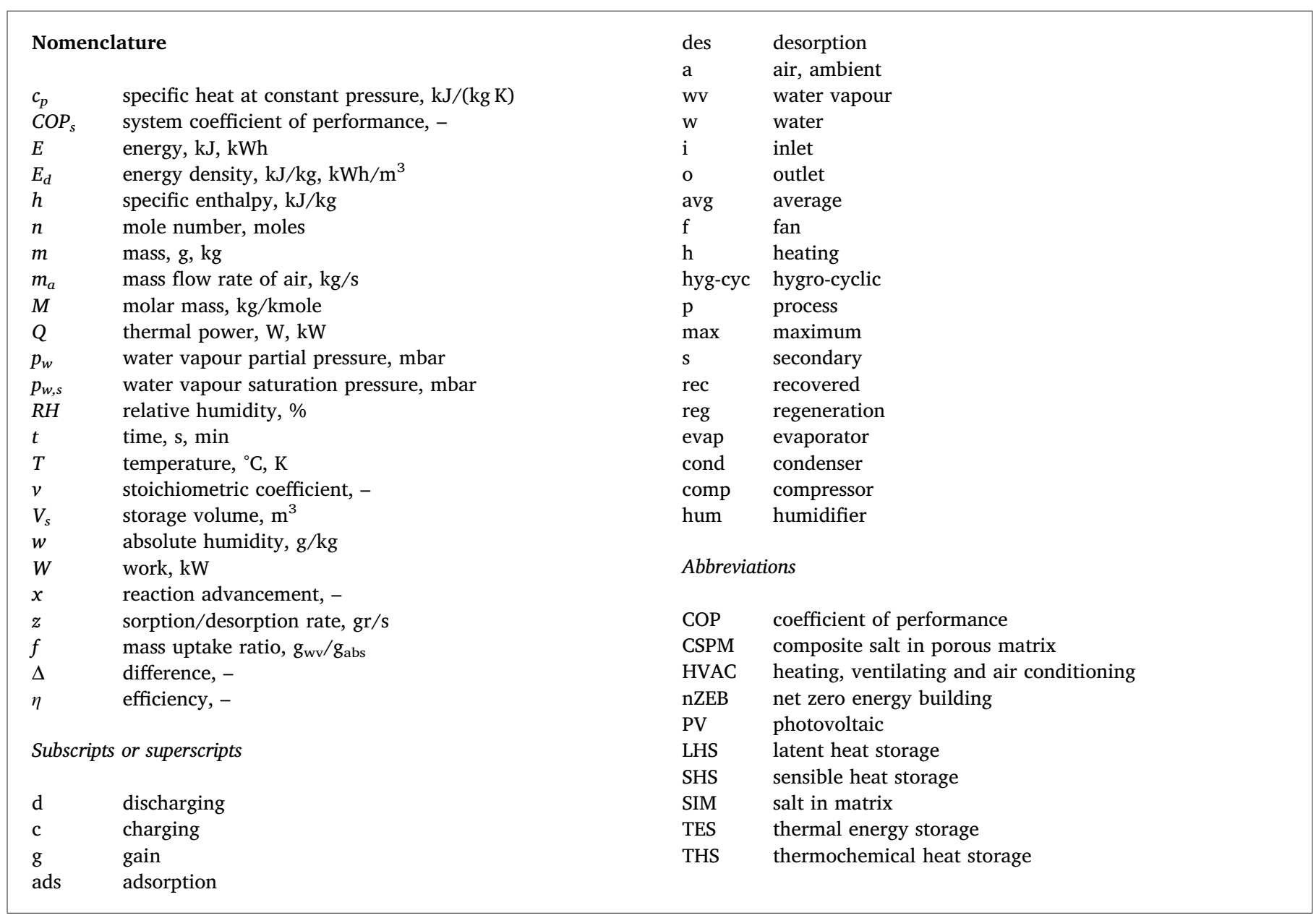

storage, utilization of PV is low as electricity can only be generated during sunlight hours whereas the majority of building energy demand is during darkness. The highest percentage ( $>40 \%$ ) of that demand is for space and water heating. In terms of energy management strategies, advanced thermal batteries could be an option to balance the mismatch between energy supply and demand in buildings. Excess electrical energy generated via PV during daytime could be converted and thus stored as heat for later usage.

In addition to storage of PV sourced electrical energy, another promising option to benefit from storage heater technologies is charging the TES sorbent using off-peak electricity. This not only helps to provide a supply-demand balance for the electrical grid, but also represents a cost-effective heating method to be used in domestic heating. For instance, in the UK, Economy 7 and Economy 10 are variable rate electricity tariffs where householders pay a different price for electricity used at different times of a day. With Economy 7, the electricity used at night costs about a third of the price of the electricity used during the day which is a considerable difference $[8,9]$.

Current electrically driven storage heater technologies use sensible heat storage (SHS) materials (i.e. bricks, water). However, low heat storage density and high heat losses remain the main barriers limiting the wider usage of these heat storage technologies. Thermochemical Heat Storage (THS) materials have several promising aspects such as low heat loss, high energy density and low space requirement [10]. In this respect, THS materials represent an important opportunity for energy storage to improve energy efficiency in buildings.

This paper investigates the development and demonstration of an electric-to-heat conversion and storage technology, which could help reduction of fossil fuel usage and achieving an energy supply-demand balance in buildings. The presented work covers the design, manufacture, and experimental/numerical investigation of a novel hybrid space heating/heat storage technology. Sensitivity analysis and optimization of the system was conducted alongside the real life operation of the system to help bridge the gap between research, development and implementation. Within this study a novel heat pump driven sorption storage heater (Heat-Store) that uses thermochemical materials as heat storage medium and that could be powered using both PV sourced electricity and off-peak electricity is proposed. The study is novel in that it combines the development of the new composite sorbents and the integration of sorption, heat pump and heat recovery technologies.

The high heat storage density and low heat losses of the proposed system could provide significant benefits such as;

- 5-6 times larger amount of heat storage for the same volume when compared with SHS and LHS respectively [10],

- A higher utilization of off-peak tariff/solar energy (i.e. solar thermal and PV),

- Flexibility in use of the storage heater (i.e. long-term heat storage),

- 2-3 times higher overall heat storage efficiency (charging + discharging).

\subsection{Background and state of the art}

Several studies on the development and characterization of new sorption materials have been performed and presented in the literature. Hongois et al. [11] developed and characterized a novel magnesium sulphate $\left(\mathrm{MgSO}_{4}\right)$ - Zeolite composite sorption material for long-term seasonal solar energy storage. Jänchen et al. [12] investigated the water adsorption characteristics of Zeolites and modified mesoporous 
materials for THS. Jänchen et al. [13] also characterized the sorption isotherms of water in potential THS materials such as low silica $\mathrm{X}$ Zeolites, microporous $\mathrm{AlPO}_{4}$, SAPO-34 and calcium chloride $\left(\mathrm{CaCl}_{2}\right)$ accommodated in the pores of attapulgite. The adsorption properties of several porous materials for solar TES and HP applications were investigated by Jänchen and Stach [14]. Aristov [15] reviewed innovative materials for adsorptive heat pumping and storage of low temperature heat which remain the current trend in these fields. Ponomarenko et al. [16] developed a new composite $\mathrm{CaCl}_{2}$ confined into mesoporous silica nanoparticle (SBA-15) pores. In a different study, Molenda et al. [17] investigated the hydration behaviour of $\mathrm{CaCl}_{2}$ at high water partial pressures for THS applications. Gordeeva and Aristov [18] studied novel two component 'composite salt in porous matrix' (CSPMs) and evaluated the current state-of-the-art and new trends in developing efficient CSPM's for various adsorption heat transformation cycles.

Korhammer et al. [19] investigated the methods to improve the less desirable properties of $\mathrm{CaCl}_{2}$ and its hydrates such as low melting points, agglomeration, low cycle stability and low sorption rates. The optimization of $\mathrm{CaCl}_{2}$ properties was achieved by mixing with $\mathrm{KCl}$ and impregnation in carrier materials to obtain a composite material. Jiang et al. [20] developed bi-salt and tri-salt composite sorbents, where expanded natural graphite treated with sulfuric acid (ENG-TSA) is integrated as the matrix with different mass ratios for heat transfer intensification. Based on testing results, the highest energy storage density of reaction heat was found as $1802 \mathrm{~kJ} / \mathrm{kg}$ and $1949 \mathrm{~kJ} / \mathrm{kg}$ for trisalt and bi-salt composite sorbents, respectively. Lizana et al. [21] reviewed the latest advances in the development of TES materials for building applications. Volumetric heat capacities of SHS, LHS, THS materials for low-to-moderate temperature applications are investigated within the study. Courbon et al. [22] developed a new composite sorbent consisting of a mesoporous silica gel impregnated with $58 \mathrm{wt} \%$ strontium bromide. A loading lift of $0.22 \mathrm{~g} / \mathrm{g}$ is obtained corresponding to an energy storage capacity of $230 \mathrm{Wh} / \mathrm{kg}$ and an energy storage density of $203 \mathrm{~kW} \mathrm{~h} / \mathrm{m}^{3}$ of packed bed composite, with an excellent stability over 14 sorption/desorption cycles.

Besides material based studies, a number of theoretical and experimental studies on the THS process have also been performed. Abedin and Rosen [23] investigated both closed and open THS systems using energy and exergy analysis methods to evaluate the charging behaviour and overall cycle performance. Mette et al. [24] developed an efficient regeneration process for an open sorption heat storage using solar-combi system as the heat source and Zeolite as the sorption material. Mette et al. [25] also investigated the performance of different reactor concepts for open sorption heat storage. Zondag et al. [26] developed and tested a small-scale packed bed open sorption heat storage prototype. It was found that a reactor loaded with $0.017 \mathrm{~m}^{3}$ of Zeolite is capable of generating $150 \mathrm{~W}$ of thermal power with an energy storage density of $\sim 0.5 \mathrm{GJ} / \mathrm{m}^{3}$. In a recent study Johannes et al. [27] developed a fixed bed Zeolite thermal heat storage system using water as the sorbate.

Tatsidjodoung et al. [28] found that an open sorption reactor loaded with $40 \mathrm{~kg}$ of Zeolite can supply a constant power of $2.25 \mathrm{~kW}$ during more than two hours corresponding to $27.5 \mathrm{~W} \mathrm{~kg}^{-1}$ of material. Michel et al. [29] developed a large scale sorption reactor consisting of multiple sorption beds with the air flow channels in between. Strontium bromide/water $\left(\mathrm{SrBr}_{2} / \mathrm{H}_{2} \mathrm{O}\right)$ as a reactive pair is used in the system.

A novel "revolving drum" reactor prototype was developed and tested by Zettl et al. [30]. Likewise, a composite sorption reactor consisting of $\mathrm{CaCl}_{2}$ impregnated mesoporous ceramic (Wakkanai siliceous shale) honeycomb filter was developed by Liu et al. [31] for low-temperature $\left(<100^{\circ} \mathrm{C}\right)$ industrial waste heat recovery.

Finck et al. [32] developed an optimal control to determine the demand flexibility of an office building equipped with a heat pump, electric heater, and thermal energy storage tanks (SHS, LHS and THS). The study introduced the instantaneous power flexibility as a power flexibility indicator. Li et al. [33] developed an innovative solar driven solid-gas sorption thermal battery where thermal energy can be stored in the form of bond energy/sorption potential at different cascaded temperatures. Donkers et al. [34] collected and analysed the thermodynamic data of 563 salt hydrate reactions that could be used to evaluate the theoretical possibilities and limitations of salt hydrates as thermochemical materials (TCMs) for seasonal heat storage in the built environment. A hydration reaction capacity larger than $2 \mathrm{GJ} / \mathrm{m}^{3}$, hydration temperature of $65^{\circ} \mathrm{C}$ or higher and a dehydration temperature below $100^{\circ} \mathrm{C}$ were considered as the evaluation criteria. Lele et al. [35] proposed a mathematical model of heat and mass transfer in a fixed-bed sorption reactor using Comsol Multiphysics 4.3a. In the study the researchers described an adaptive modelling approach and established a set of partial differential equations describing the physical system and appropriate parameters for simulating the thermal decomposition process. Scapino et al. [36] reviewed long-term sorption heat storage at both the material and prototype scales. The study particularly targeted the applications requiring heat within a temperature range of $30-150{ }^{\circ} \mathrm{C}$ such as space heating, domestic hot water production, and some industrial processes. In another study, Fumey et al. [37] developed a liquid absorption heat-mass exchanger using sodium hydroxide as the absorbent for heat storage applications. The system provided a maximum temperature lift of $35 \mathrm{~K}$ for the absorbent concentration in the range of $50-27 \mathrm{wt} \%$ for one continuous process. Jiang et al. [38] investigated a modular sorption thermal cell using natural graphite treated with sulfuric acid for cold and heat cogeneration. The results indicated that heat density ranged between 580 and $1368 \mathrm{~kJ} / \mathrm{kg}$ whereas cold density was between 400 and $1134 \mathrm{~kJ} / \mathrm{kg}$. Ströhle et al. [39] developed a novel TES concept that allows the outflow temperature of the heat-transfer fluid (HTF) to be controlled during discharging. The concept is based on placing a THS section on top of an SHS section. The simulations demonstrated the ability to maintain a constant HTF outflow temperature during discharging.

Despite several sorption materials and processes being reported in the literature, no research has focused on integrating HP, THS and heat recovery technologies for energy efficient heat storage and space heating proposes. Utilizing the moisture desorbed in the charging cycle of a THS system through the use of a two stage heat recovery system (i.e. HP evaporator and heat exchanger), represents an important opportunity to improve the overall heat storage efficiency. This process provides a reduced energy requirement from the HP and reduced waste heat during system operation thereby resulting in an efficient energy storage method for buildings.

The aim of this study was to demonstrate a novel concept for the effective conversion and storage of renewably sourced (or low cost) electrical energy to heat energy in buildings. In order to achieve this aim three objectives were set;

- To synthesize new composite sorbents using the "salt in matrix" (SIM) method $[18,40]$;

- To design and develop a $6 \mathrm{kWh}$ multilayer fixed bed sorption reactor;

- To install the heat pump driven sorption storage heater and investigate its thermal performance of five different sorbents under different humidity conditions.

\section{Selection and synthesis of sorption materials}

In order to meet the first objective of the study, five different sorbents were proposed for testing in a novel prototype system. Four sorbents were salt based composites (SIM's) and one was Zeolite 13X. The SIM composites were;
a. SIM-3a (Vermiculite $+43 \mathrm{wt} \% \mathrm{CaCl}_{2}$ ),
b. SIM-3m (Vermiculite $+35 \mathrm{wt} \% \mathrm{MgCl}_{2}$ ),
c. SIM-3cl (Vermiculite $+22 \mathrm{wt} \% \mathrm{CaCl} 2+17 \%$ wt $\mathrm{LiCl}$ ), 


\section{d. SIM3ml (Vermiculite +18 wt $\% \mathrm{MgCl}_{2}+17 \%$ wt LiCl).}

Among the five sorption materials, SIM-3a and Zeolite 13X have been investigated in previous stages of this research and comparatively analysed under different experimental test configurations [41-43]. In addition to these materials, $\mathrm{MgCl}_{2}$ was selected from the literature [26] due to its high $E_{d}$ and LiCl is selected due to its steady hygrothermal performance (e.g. sorption rate, heat supply) over typical discharging cycles. LiCl was used only as a support material in modified SIM-3a and SIM-3m composites as it is not suitable for independent use due to its high cost and highly corrosive nature. The aim was to stabilize the performance of the modified SIM-3a and SIM-3m with the contribution of LiCl to obtain a steadier discharging performance. SIM-3a and SIM$3 \mathrm{~m}$ composites were also examined without any modification to evaluate the influence of $\mathrm{LiCl}$ on their performance.

Prior to preparation of large quantities of composite sorbents for experimental testing, small quantities of the materials; SIM-3a, SIM-3cl, SIM-3m, SIM-3ml, raw vermiculite and Zeolite $13 \mathrm{X}$ were synthesized for characterization.

Scanning Electron Microscopy (SEM) images of the salt impregnated vermiculite samples, raw vermiculite sample and the Zeolite $13 \mathrm{X}$ sample are presented in Fig. 1(a-f). The raw vermiculite surface consists of thin lamellas that significantly increase surface area for salt impregnation (See Fig. 1f). As presented in Fig. 1a-d, each salt creates a unique structure on the vermiculite surface. Whilst $\mathrm{CaCl}_{2}$ settles between the layers of lamellar (See Fig. 1a), LiCl is absorbed by the layers creating damage on the lamellar surface structure (See Fig. 1b). In contrast, $\mathrm{MgCl}_{2}$ adheres to the lamellas as a coating (See Fig. 1c) and crystallizes in various sizes as seen in Fig. 1d. In Fig. 1e, the highly porous structure of Zeolite 13X cannot be imaged due to the sub-mesoporous nature of the sorbent.

\section{Experimental study}

\subsection{Methodology}

The methodology of the experimental work is designed and is presented in Fig. 2. The first phase of experimental work was to test the selected sorption materials under both low and high inlet air humidity. High humidity tests were performed under $\mathrm{RH}_{\text {air }}=80 \%$ and low humidity test were performed under $R_{\text {air }}=60 \%$ conditions where ambient temperature was kept constant at $T_{a} \approx 17^{\circ} \mathrm{C}$. The low humidity cycles investigated the thermal energy output of the sorbents at low sorption rates with a one cycle test at low $R H_{\text {air }}$ performed for each sorption material. For the high humidity tests, two repeating cycles were performed. In the first tests the increase in sorption rate and heat output of each material were investigated. In the following round, the cyclic stability of the sorbents at $T_{c} \approx 85^{\circ} \mathrm{C}$ was investigated. Upon
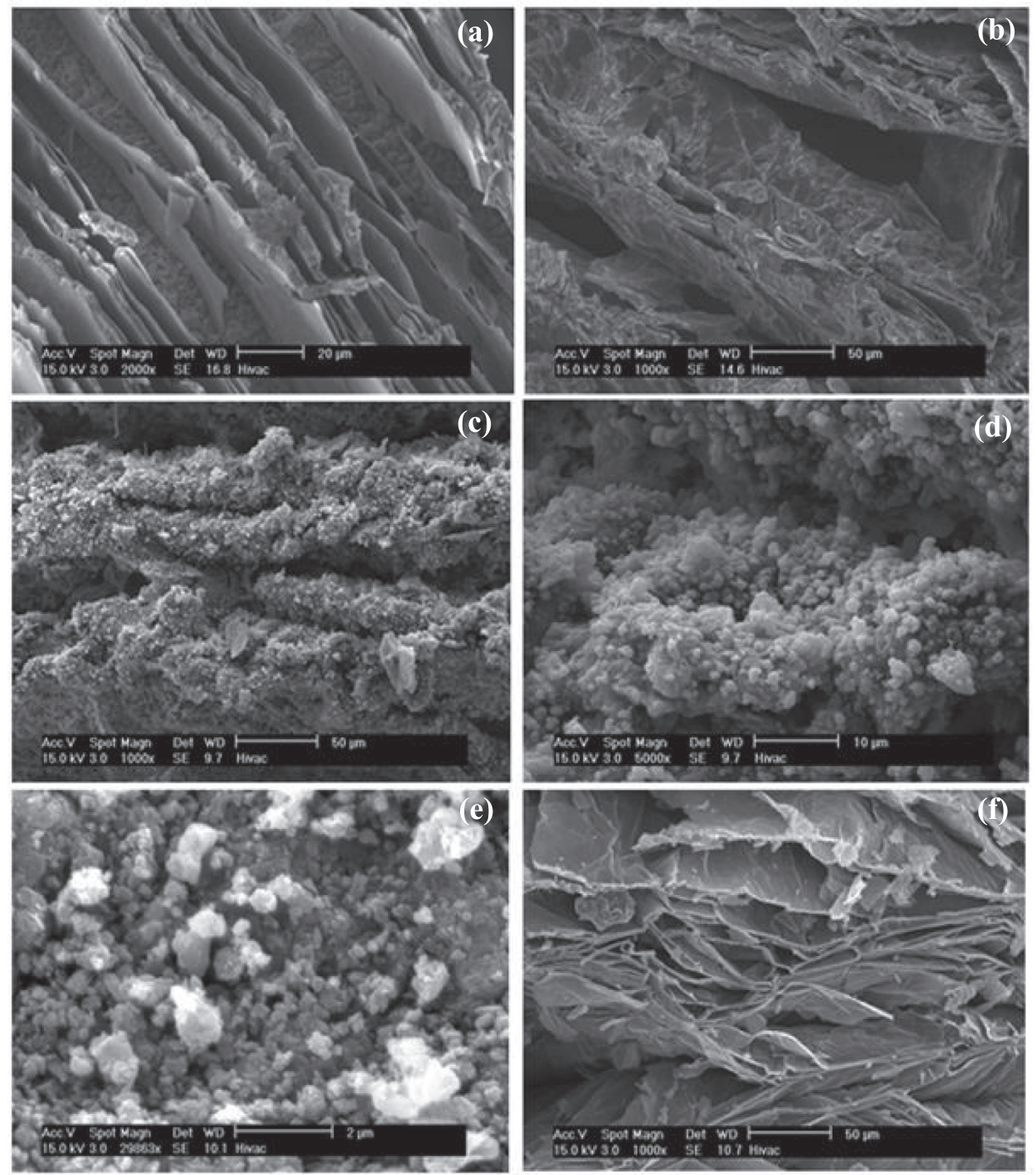

Fig. 1. SEM images of candidate materials; (a) SIM3a, (b) SIM-3cl (c) SIM-3m, (d) SIM-3ml, (e) Zeolite 13X, (f) Raw vermiculite. 


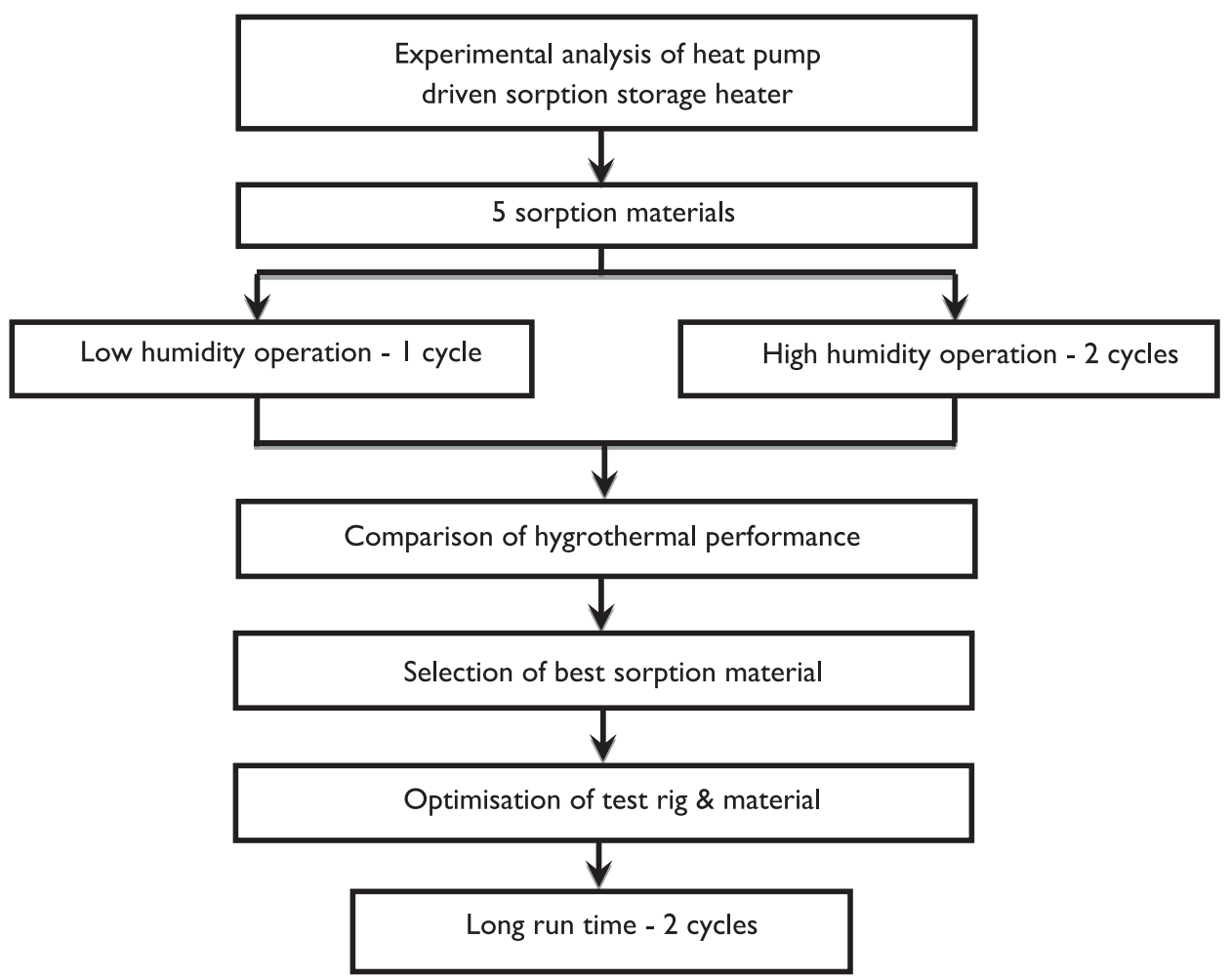

Fig. 2. Flowchart illustrating the experimental methodology.

completion of the tests at low and high humidity conditions, the hygrothermal performance of all materials and overall system performance were comparatively analysed. Based on the analysis results the best sorption material was then selected. In the final step of experimental work, 2 long cycle tests using the optimized system and selected sorption material were performed with the aim of investigating the systems overall performance within these cycles.

\subsection{Process design and system operation}

The schematic illustrations of the charging and discharging operations of the proposed system are presented in Fig. 3a and b with a description of the flow numbers also provided in Table 1 . As can be seen from Fig. 3a, during the discharging cycle, the generated sorption heat is transferred to the air which could theoretically be used directly for space heating. In the charging cycle, an energy efficient process is used

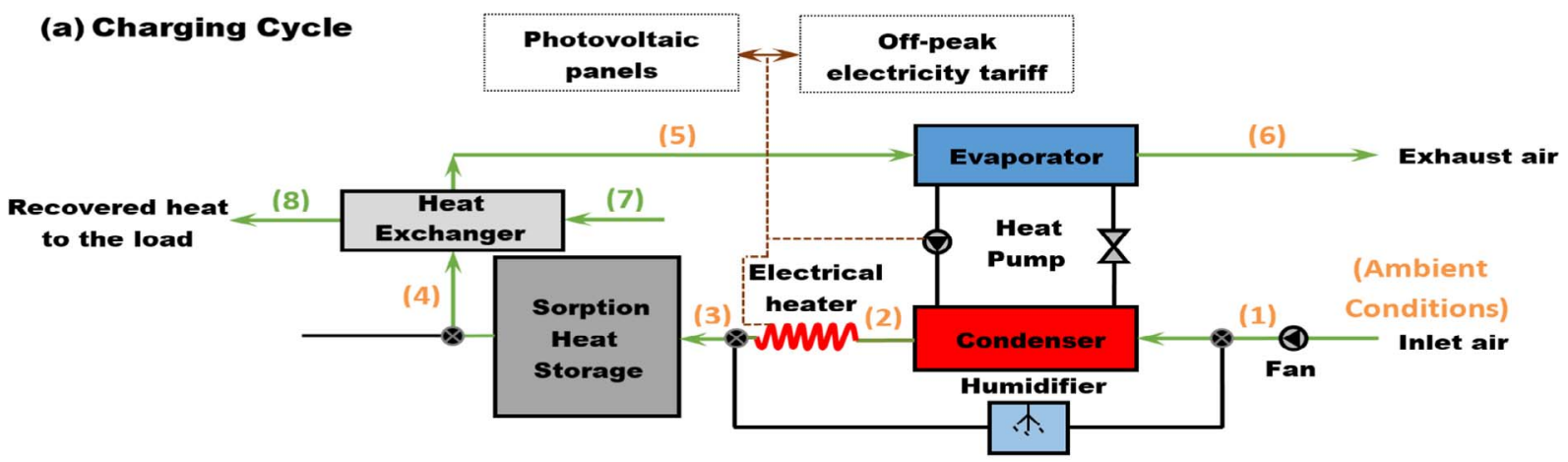

(b) Discharging Cycle

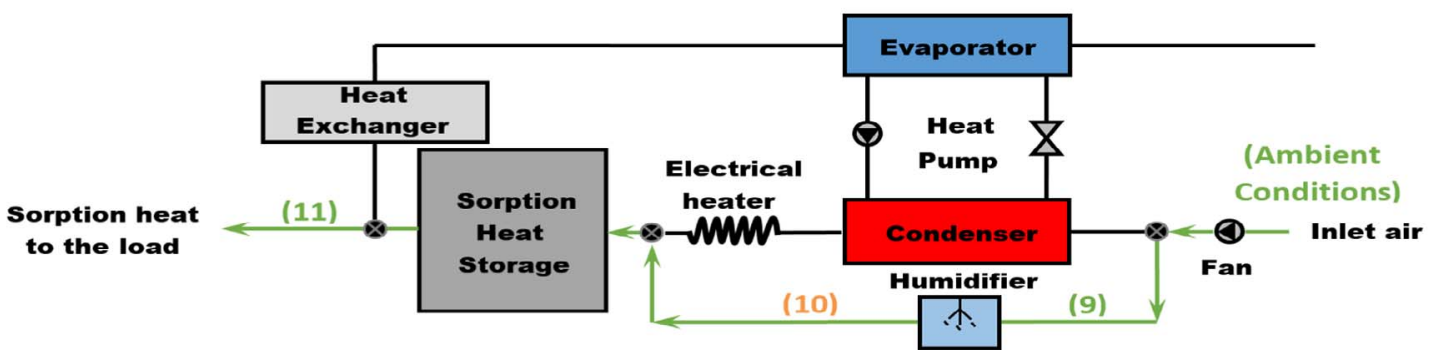

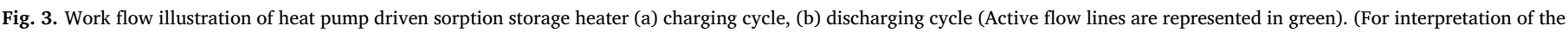
references to color in this figure legend, the reader is referred to the web version of this article.) 
Table 1

Description of flow numbers in the experimental work flow diagram.

\begin{tabular}{llll}
\hline \multirow{2}{*}{ Charging } & & \multicolumn{2}{l}{ Discharging } \\
\hline 1 & System inlet & 9 & System inlet \\
2 & HP condenser outlet & 10 & Humidifier outlet \\
3 & EH outlet - reactor inlet & 11 & Reactor outlet \\
4 & Reactor outlet - HEX inlet & & \\
5 & HEX outlet - HP evaporator inlet & & \\
6 & HP evaporator outlet- exhaust & & \\
7 & HEX inlet (secondary air flow) & & \\
8 & HEX outlet (secondary air flow) & & \\
\hline
\end{tabular}

for desorbing the water from the sorbent. Here, the air is initially heated in the heat pump (HP) condenser. The air temperature is then boosted by the electrical heater (EH). Heat is then partially transferred to the sorbent to aid the endothermic dehydration process. Part of the waste heat (i.e. air leaving the reactor) is then utilized for heating the secondary air stream via a heat exchanger. In the final stage, the remainder of the waste heat is transferred to the refrigerant and the air is exhausted to the ambient.

Photograph and a schematic illustration of the experimental test rig are given in Figs. 4 and 5 respectively. During the charging process an air to air heat pump is used. A heat pump was chosen as firstly, it enables the desired air inlet temperature to be achieved with less energy consumption when compared with the sole use of a direct electrical heater. Secondly, as the refrigerant temperature is very low in the evaporator, waste heat from the reactor exhaust air could be recovered effectively by condensing the moisture. Using a heat exchanger alone would limit the amount of recovered heat as it is highly unlikely to cool the air to its dew point temperature. The combined use of both heat recovery and the heat pump enables a more effective recovery of waste heat.

In the proposed system, a novel multilayer fixed bed sorption reactor (See Fig. 6) was used. As the system is charged with electricity sourced from the HP and EH, moisture desorption should be effective both for a higher rate of heat recovery (i.e. high rate of vapour condensation) and also for reducing the operational time of both the HP and EH. Therefore, a uniform air flow through the sorption bed is critical. In any particular reactor design, with increasing bed thickness, resistance to air flow increases which could lead to insufficient heat transfer to the sorbent and thereby a longer charging time. To overcome this resistance, it was decided to use multiple sorption beds with lower bed thickness with air channels between each bed to increase the uniformity of the air flow.

Inside the reactor, there are four air inlet channels between the sorption beds where the channel ends are sealed. Air entering the channels is forced to flow through the sorption beds (up and down) before following the outlet channels to leave the reactor. Eight trays, made up of $1.2 \mathrm{~mm}$ thick aluminium mesh, are used in the reactor (See Fig. 6a) where each tray has dimensions of $h: 50 \mathrm{~mm}$, l: $400 \mathrm{~mm}$ and $w$ : $400 \mathrm{~mm}$. The maximum sorbent volume of each tray is $8 l$ corresponding to a total reactor volume, $V_{s}$ reactor of $64 l$. The distance between the trays, constituting the air flow channels was designed as $20 \mathrm{~mm}$. The 3D schematic illustration and view of the sorption reactor in construction stage showing the inlet and outlet air channels is presented in Fig. 6a and b. The final version of the constructed sorption reactor is also presented in Fig. 7.

It is proposed to provide continuous space heating with the use of the newly developed sorption storage heater. During the discharging cycle, free sorption heat is utilized for heat supply where the only energy consuming components are the fan and humidifier $(100 \mathrm{~W})$. During the charging cycle, whilst off peak or PV sourced electricity is used for charging the heat storage material, waste heat is also recovered and supplied to the building.

\subsection{Equations and working principles}

The formulas used to analyse the system performance are presented, with their definitions as follows.

In charging cycle, heat transferred from the charging exhaust air to the secondary air stream is equal to the recovered useful heat, $Q_{\text {rec }}$. The energy balance between process air and secondary air stream is given in Eq. (1):

$m_{a, p} \times\left(h_{4}-h_{5}\right)=m_{a, s} \times\left(h_{8}-h_{7}\right)=Q_{\text {rec }}$

The specific enthalpy of the air for any certain moisture, $w_{x}$ or temperature, $T_{x}$ condition, is calculated using Eq. (2) [44]. Here, the first and second parts of the equation represent the specific enthalpy of the dry air and water vapour respectively:

$h_{x}=1.006 \times T_{x}+\left[w_{x} \times\left(1.84 \times T_{x}+2501\right)\right]$

The absolute humidity of air at any specific Relative Humidity, $R H_{x}$ and $T_{x}$ condition is defined as in Eq. (3) [45]:

$w=216.7 \times\left[\frac{\frac{R H}{100 \%} \times 6.112 \times \exp \left(\frac{17.62 \times T}{243.12+T}\right)}{273.15+T}\right]$

$R H$ is the ratio of the moisture content of the air to the saturation moisture content at any specific condition $(P, T)$. $R H$ could also be expressed as the ratio of vapour partial pressure to the saturation vapour partial pressure at actual dry bulb temperature of air as given in the Eq. (4):

$R H=\frac{p_{w}}{p_{w, s}}$

The sum of the compressor work and the heat gain in the HP evaporator is equal to the heat output at the HP condenser. Based on the energy balance of the HP, enthalpy change of the air could be calculated with the Eq. (5) [44] and Eq. (6):

$Q_{\text {evap }}+W_{\text {comp }}=Q_{\text {cond }}$

$m_{a, p} \times\left(h_{5}-h_{6}\right)+W_{c o m p}=m_{a, p} \times\left(h_{2}-h_{1}\right)$

Based on the product-fuel principle, the heat pump COP is equal to the ratio of heat output at the condenser to the electrical power input to the compressor as given in Eq. (7) [44] below:

$C O P_{H P}=\frac{Q_{\text {cond }}}{W_{\text {comp }}}$

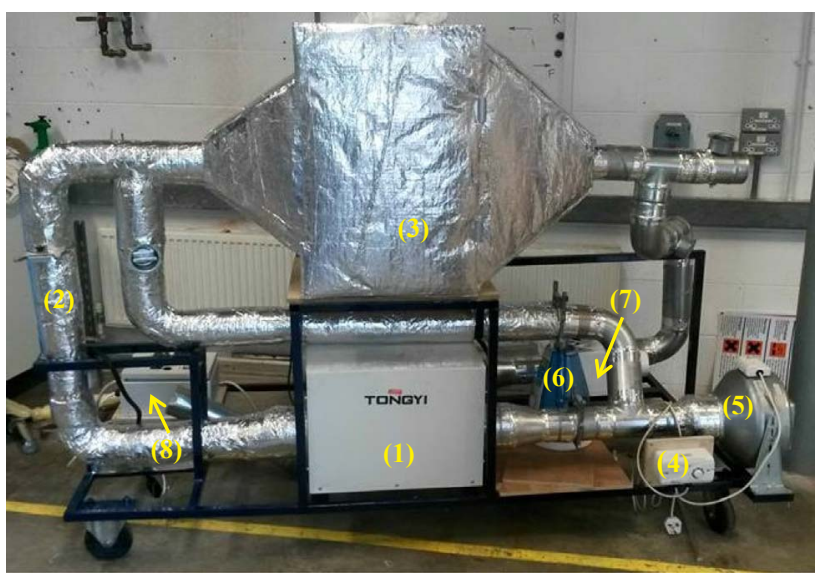
(1) Heat pump
(5) Fan
(2) Electric coil
(6) Ultrasonic humidifier
(3) Sorption reactor
(7) Air-to-air heat exchanger
(4) Fan speed controller
(8) PID controller

Fig. 4. View of the experimental rig. 


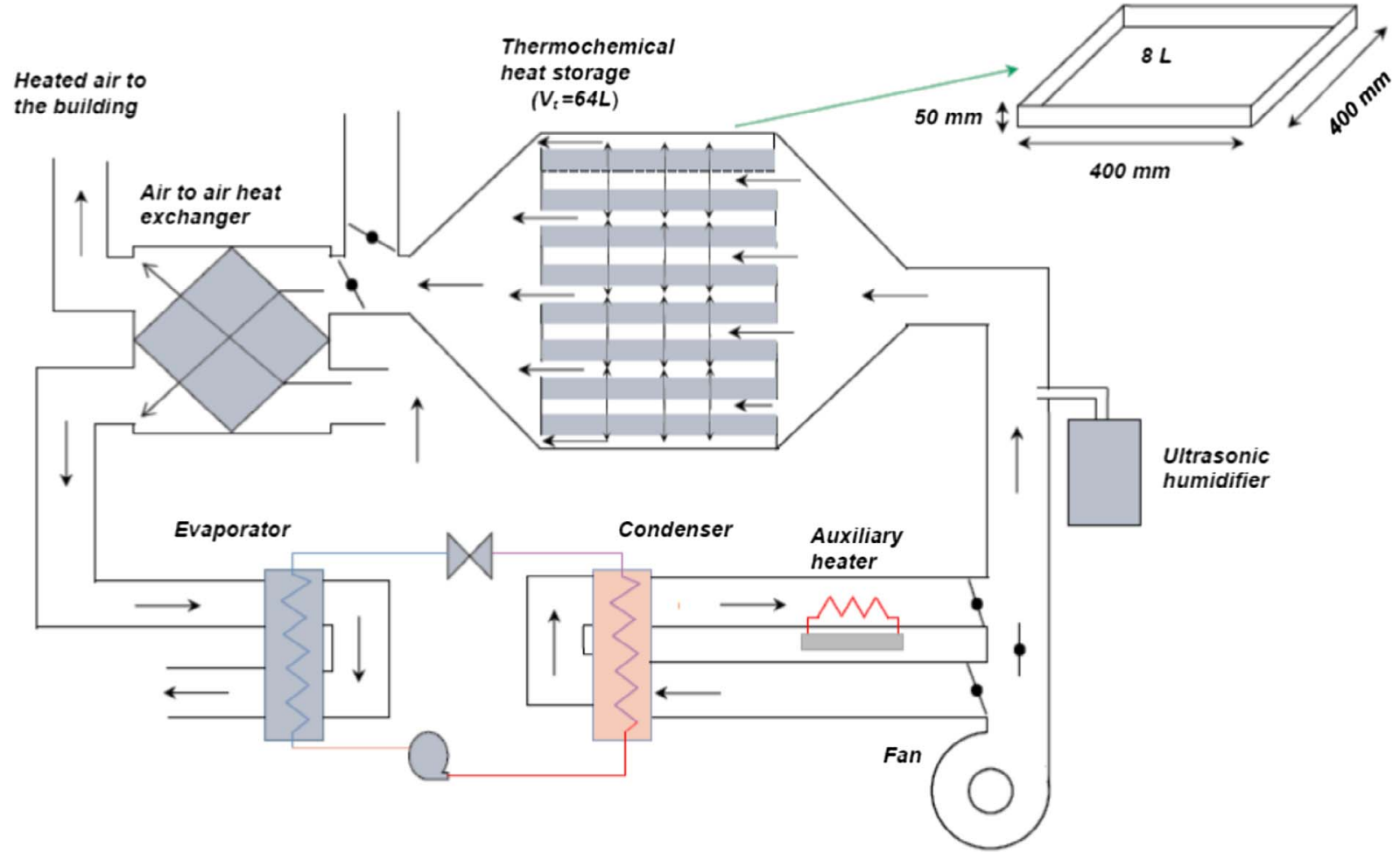

Fig. 5. Schematic illustration of the experimental rig.

$Q_{\text {cond }}$ is defined as the enthalpy difference of the air between the condenser outlet and inlet and $W_{\text {comp }}$ is equal to the difference between $Q_{c o n d}$ and $Q_{\text {evap. }}$. Inserting Eqs. (5) and (6) into Eq. (7), allows the $C O P_{H P}$ to be obtained as in Eq. (8) below:

$C O P_{H P}=\frac{m_{a, p} \times\left(h_{2}-h_{1}\right)}{m_{a, p} \times\left[\left(h_{2}-h_{1}\right)-\left(h_{5}-h_{6}\right)\right]}$

The electrical resistance heater is used to boost the air temperature before it enters the sorption reactor. Here, the thermal power transferred to the air is equal to the electrical power input to the electrical heater. Assuming that the air duct is well insulated $Q_{l}=0$, the energy balance is written as follows:

$m_{a, p} \times\left(h_{3}-h_{2}\right)=W_{E H}$
In the charging process, the difference of the specific enthalpy of air at the sorption reactor inlet and outlet is equal to the product of the specific desorption enthalpy of the sorbent $\left(\mathrm{kJ} / \mathrm{kg}_{\mathrm{wv}}\right)$ and the amount of desorbed water vapour. The energy equilibrium of the sorption reactor can then be written as follows [46]:

$$
m_{a, p} \times\left[\left(T_{3} \times C_{p, a}+w_{3} \times T_{3} \times C_{p, w}\right)-\left(T_{4} \times C_{p, a}+w_{3} \times T_{4} \times C_{p, w}\right)\right]_{t_{c}}
$$$$
=\Delta h_{w} \times m_{a, p} \times\left(w_{4}-w_{3}\right)
$$

Simplifying the above formula, Eq. (11) is obtained as below [47];

$\left[\frac{T_{3}-T_{4}}{w_{4}-w_{3}}\right]_{t_{c}}=\frac{\Delta h_{w}}{C_{p, a}+\left(w_{3} \times C_{p, w}\right)}$

The state of the sorbent during the charging process is defined using the reaction advancement, $X[29,47]$. Reaction advancement varies in the
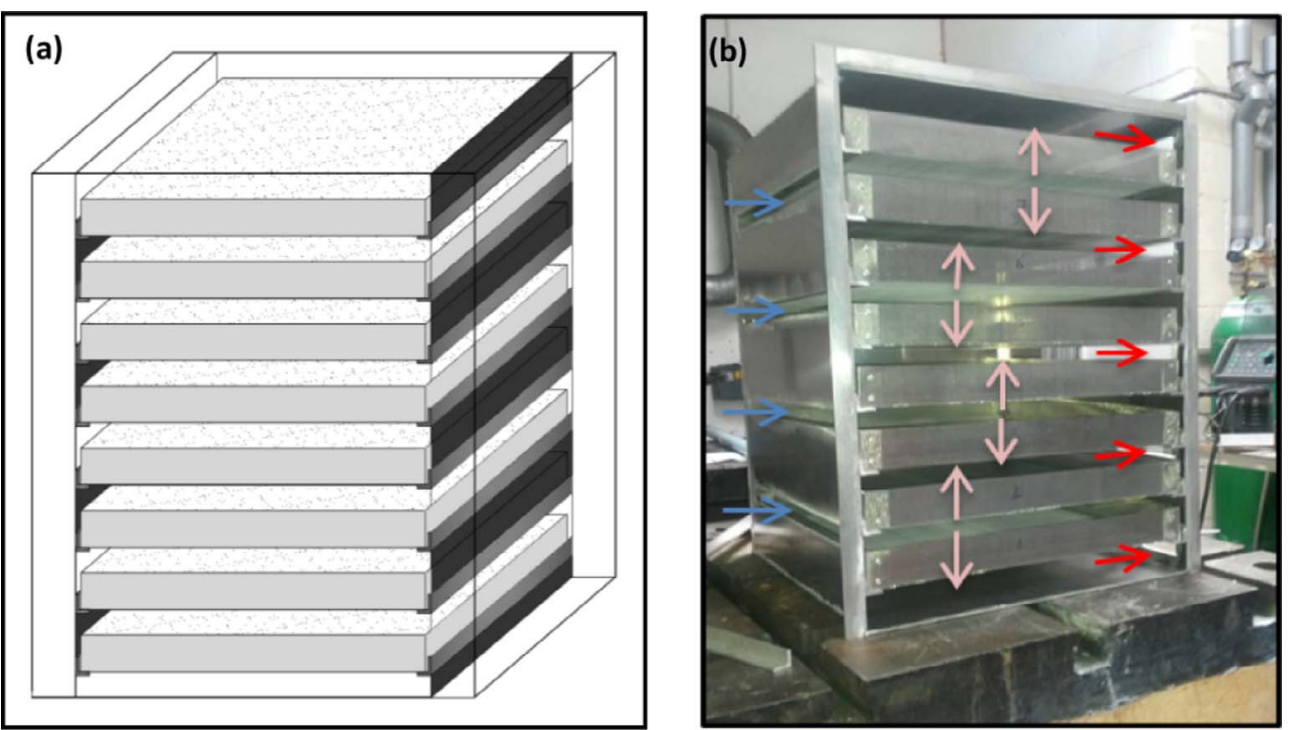

Fig. 6. (a) Schematic illustration and (b) view of the sorption reactor in construction stage showing the inlet and outlet air flow channels. 


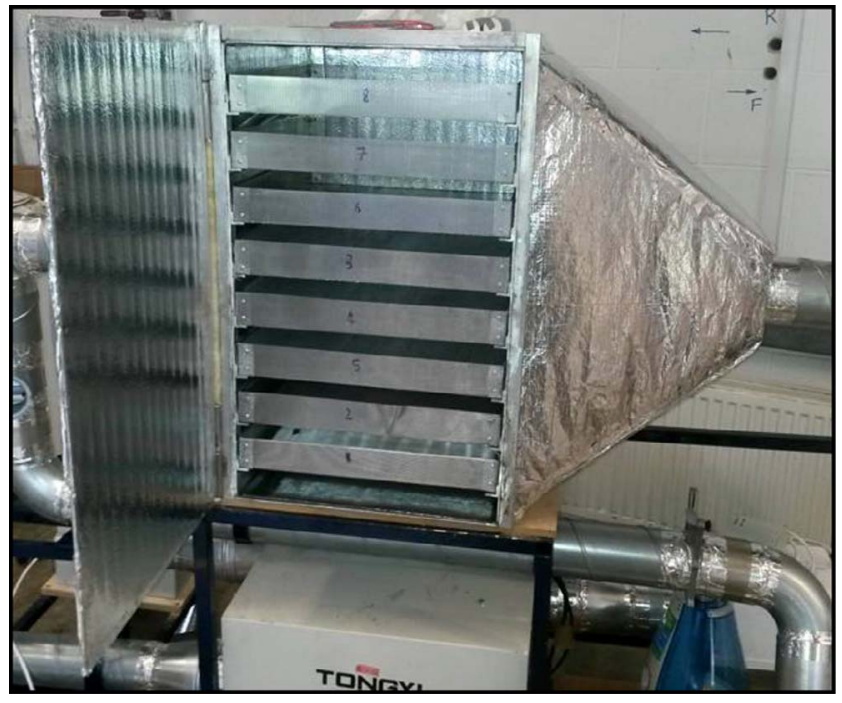

Fig. 7. View of the constructed multi-layer fixed bed sorption reactor.

range of $0 \rightarrow 1$ where 0 , represents a dehydrated (anhydrous) state whilst 1 represents the equilibrium (saturated) state of the sorbent.

$X_{c}=\frac{m_{a, p} \times \int_{t_{0}}^{t_{c}}\left(w_{4}-w_{3}\right) d t}{v \times n \times M_{m, w}}$

Here, time dependant variation of $w_{4}$ is calculated as:

$W_{4}\left(t_{c}\right)=w_{4, i}-\frac{d w_{4}}{d t} \times t_{c}$

The total desorbed moisture over a time frame, $t_{c}$ during the charging process is calculated using Eq. (14):

$M_{t, c}=60 \times m_{a, p} \times\left(\int_{0}^{t_{c}}\left(w_{4}-w_{3}\right) d t\right)$

Inserting Eq. (13) into Eq. (14), Eq. (15) is obtained as:

$M_{t, c}=60 \times m_{a, p} \times \int_{0}^{t_{c}}\left(\left(w_{4, i}-\frac{d w_{4}}{d t} \times t_{c}\right)-w_{3}\right) d t$

During the discharging cycle, system inlet temperature could be considered as equal to the ambient;

$T_{1}=T_{a}$

The general energy balance of the humidification process for the discharging cycle is defined as follows:

$m_{a, p} \times h_{9}=m_{a, p} \times h_{10}$

Substituting $h_{9}$ and $h_{10}$ with their expression given in Eq. (2), the following equation is obtained:

$$
\begin{aligned}
1.006 \times T_{9}+\left[w_{9} \times\left(1.84 \times T_{9}\right.\right. & +2501)]=1.006 \times T_{10} \\
+ & {\left[w_{10} \times\left(1.84 \times T_{10}+2501\right)\right] }
\end{aligned}
$$

The simplified version of the energy balance, based on the air psychrometric conditions ( $T$ and $w$ ) at the humidifier inlet and outlet, is written as follows:

$1.006 \times\left(T_{9}-T_{10}\right)+1.84 \times\left(w_{9} \times T_{9}-w_{10} \times T_{10}\right)-2501 \times\left(w_{9}-w_{10}\right)=0$

The sorption heat gained by the air, $Q_{g}$, during the adsorption process is defined with Eq. (20):

$Q_{g}=m_{a, p} \times\left(h_{11}-h_{10}\right)$

Assuming that there is no heat loss in the sorption reactor, the relationship between the sorption specific enthalpy $\left(\mathrm{kJ} / \mathrm{kg}_{\mathrm{wv}}\right)$ of the adsorbent and enthalpy change of air is calculated with the following Eq.
(21) [47]:

$\left[\frac{T_{11}-T_{10}}{w_{10}-w_{11}}\right]_{t_{c}}=\frac{\Delta h_{w}}{C_{p, a}+\left(w_{11} \times C_{p, w}\right)}$

The reaction advancement during the discharging process is defined as follows [29,47]:

$X_{d}=\frac{m_{a, p} \times \int_{t_{0}}^{t_{d}}\left(w_{10}-w_{11}\right) d t}{v \times n \times M_{m, w}}$

In contrast to the $X_{\mathcal{c}}$, given in Eq. (12), $X_{d}$ represents the vapour pressure level of the sorbent and defines how close the sorbent is to its saturation point. As the material moisture content increases, its state changes from anhydrous to hydrate which is represented with the scale of $0 \rightarrow 1$. Therefore, in any moment, $t_{d}$ the sum of $X_{\mathrm{c}}$ and $X_{d}$ should be equal to 1 ;

$X_{c}+X_{d}=1$

Here discharging supply air humidity, $w_{11}$ is calculated with the Eq. (24) as below;

$W_{11}\left(t_{d}\right)=w_{11, i}+\frac{d w_{11}}{d t} \times t_{d}$

The total moisture uptake of the sorbent in a discharging period, $t_{d}$ is calculated using Eq. (25);

$M_{t, d}=60 \times m_{a, p} \times\left(\int_{0}^{t_{d}}\left(w_{10}-w_{11}\right) d t\right)$

By replacing the term $w_{11}$ with the formulation given on the right hand side of Eq. (26) we get;

$M_{t, d}=60 \times m_{a, p} \times \int_{0}^{t_{d}}\left(w_{10}-\left(w_{11, i}+\frac{d w_{11}}{d t} \times t_{d}\right)\right) d t$

Assuming that any moisture adsorbed in a period, $t_{d}$ should be equal to the moisture desorbed in duration of $t_{c}$, Eq. (27) balances as follows;

$M_{t, d}=-M_{t, c}$

Here the required $t_{c}$ after the discharging process with a length of $t_{d}$ is calculated by solving Eqs. (15) and (26). The ratio of $t_{c}$ to $t_{d}$ for any particular operational condition is defined as $t_{x}$;

$\frac{t_{c}}{t_{d}}=t_{x}$

During the discharging process, in any moment, $t_{d}$, the total heat output is equal to the sorption heat gained by the air;

$W_{o, d}=Q_{g}$

The fan and humidifier are the only energy consuming components during the discharging process. The total electric power input to the system is thus defined as follows;

$W_{i, d}=W_{\text {hum }}+W_{f}$

In the charging process, the HP compressor and, depending on the regeneration temperature requirement, the electrical heater constitute the highest share of electrical power input along with a low amount of electrical power for the fan;

$W_{i, c}=W_{\text {comp }}+W_{E H}+W_{f}$

The waste heat from the charging exhaust air is partially recovered in the air-to air heat exchanger and it is considered as useful heat gain during the charging process;

$W_{o, c}=Q_{\text {rec }}$

The total energy output $\left(E_{o, t}\right)$ and input $\left(E_{i, t}\right)$ for one full cycle (charging + discharging) heat storage process is calculated using Eqs. (33)-(35) respectively; 
$E_{o, t}=\int_{0}^{t_{d}} W_{o, d} d t+\int_{0}^{t_{c}} W_{o, c} d t$

$E_{i, t}=\int_{0}^{t_{d}} W_{i, d} d t+\int_{0}^{t_{c}} W_{i, c} d t$

The total system COP is then defined as the ratio of total energy output to the total energy input as given below;

$C O P_{S}=\frac{E_{o, t}}{E_{i, t}}$

\subsection{Uncertainty analysis}

In the experimental rig, eight sensor locations were used to determine the $T$ and $R H$ at the inlet and outlet of the HP, HEX, sorption reactor and EH. System inlet/ambient conditions were also recorded for both charging and discharging cycles. The data was recorded using the EK-H4 Eval Kit for Temperature - Humidity Sensors from Sensirion, AG, Switzerland. The experimental uncertainties were determined by applying Gauss propagation law [48].

The independent parameters measured in the experiments (i.e. temperatures and relative humidities) were;

- System inlet $\left(T_{1}, R H_{1}\right)$,

- Humidifier outlet $\left(T_{2}, R H_{2}\right)$,

- HP condenser outlet $\left(\mathrm{T}_{3}, \mathrm{RH}_{3}\right)$,

- EH outlet $\left(T_{4}, \mathrm{RH}_{4}\right)$,

- Reactor outlet $\left(T_{5}, R_{5}\right)$,

- HEX inlet $\left(T_{6}, R_{6}\right)$,

- HEX outlet $\left(T_{7}, \mathrm{RH}_{7}\right)$,

- HP evaporator outlet (exhaust) $\left(T_{8}, R H_{8}\right)$.

The Mass Flow Rate (MFR) of air $\left(m_{a}\right)$ was also measured to determine the heat transfer rates. The experiments were conducted using

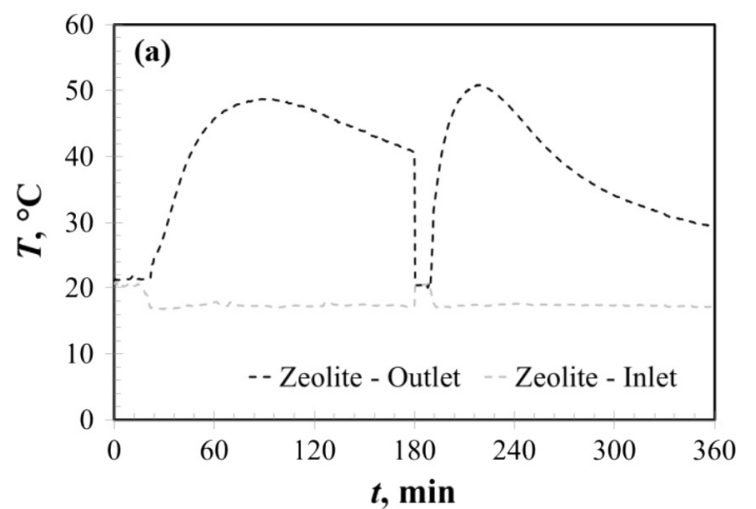

the following instruments: Thermocouples with the maximum deviation of $\pm 0.3^{\circ} \mathrm{C}$ for temperature and $\pm 2 \%$ for relative humidity and air mass flow meter with the accuracy of $\pm 2 \%$.

From Eqs. (1)-(35) it is noted that the $C O P_{s}$ is a function of the measured eight $T$ and $R H$ values for the charging cycle, the measured two $T$ and $R H$ (system inlet, reactor inlet and reactor outlet) values during the discharging cycle also the measured $m_{a}\left(m_{a, c}, m_{a, d}\right)$ in both cycles, with each subject to uncertainty:

$C O P_{S}=f\left(T_{1 \rightarrow 8}, R H_{1 \rightarrow 8}, T_{9 \rightarrow 11}, R H_{9 \rightarrow 11}, m_{a, c}, m_{a, d}\right)$

Where subscripts $1 \rightarrow 8$ stand for eight measurements points in the system during the charging cycle and $9 \rightarrow 11$ representing the three measurement points during the discharging cycle as described above.

Thus the total uncertainty of the overall system efficiency can be expressed as;

$$
\begin{aligned}
w_{R}= & {\left[\sum_{1}^{8}\left[\left(\frac{\partial C O P_{S}}{\partial T_{1 \rightarrow 8}} w_{T_{1 \rightarrow 8}}\right)^{2}\right]+\sum_{1}^{8}\left[\left(\frac{\partial C O P_{S}}{\partial R H_{1 \rightarrow 8}} w_{R H_{1 \rightarrow 8}}\right)^{2}\right]\right.} \\
& +\left(\frac{\partial C O P_{S}}{\partial m_{a, c}} w_{m_{a, c}}\right)^{2}+\sum_{9}^{11}\left[\left(\frac{\partial C O P_{S}}{\partial T_{9 \rightarrow 11}} w_{T_{9 \rightarrow 11}}\right)^{2}\right] \\
& \left.+\sum_{1}^{8}\left[\left(\frac{\partial C O P_{S}}{\partial R H_{9 \rightarrow 11}} w_{R H_{9 \rightarrow 11}}\right)^{2}\right]+\left(\frac{\partial C O P_{S}}{\partial m_{a, d}} w_{m_{a, d}}\right)^{2}\right]^{1 / 2}
\end{aligned}
$$

The total uncertainty rate affecting the efficiency of the proposed system was computed using Eq. (37). The estimation implies that total uncertainty in calculation of the efficiency was found to be $3.36 \%$.

\section{Results and discussion}

\subsection{Material hygrothermal performance under high air humidity operating conditions}

The first stage of testing involved a two cycle test of the synthesized

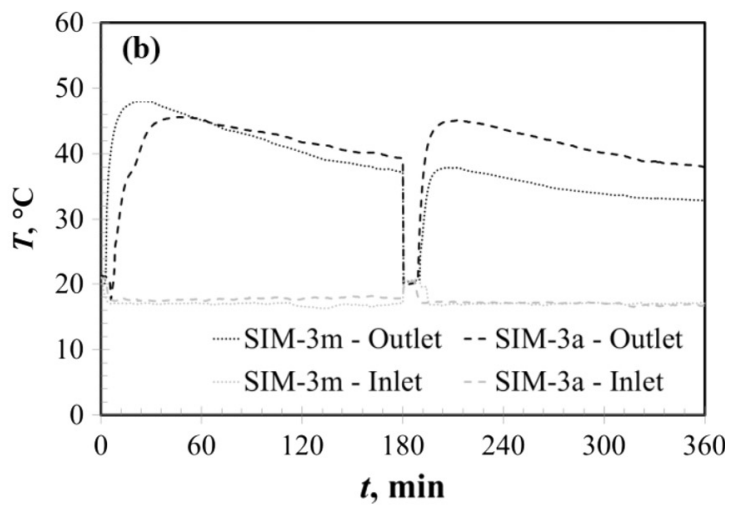

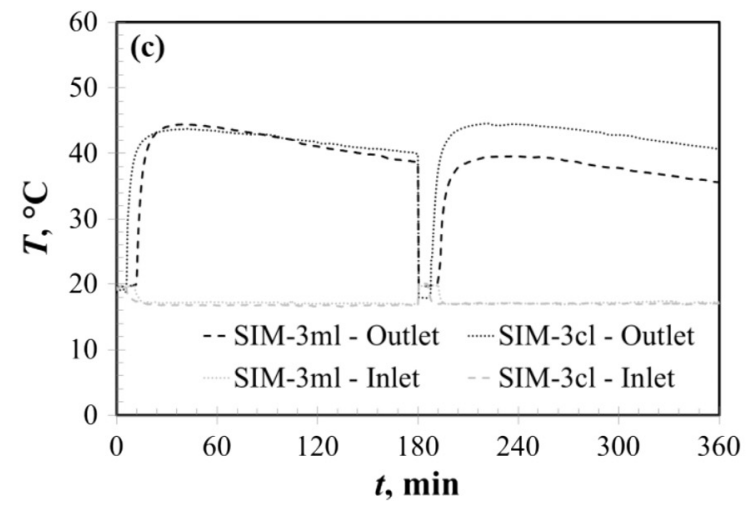

Fig. 8. Experimental results of the two cycle testing of synthesized sorption materials under high humidity conditions. 
sorption materials under high humidity conditions $\left(R H_{i}=80 \%\right.$ and $T_{i}=17^{\circ} \mathrm{C}, P_{v}=16.4 \mathrm{mbar}$ ) in the prototype. All materials were dried in the oven at $T=150^{\circ} \mathrm{C}$ for $t=48 \mathrm{~h}$ prior to performing the tests to ensure that any residual moisture was removed. As can be seen from Fig. 8a-c, for the initial cycles. all materials provided peak output temperature, $T_{o}$ in the range of $40^{\circ} \mathrm{C} \rightarrow 50{ }^{\circ} \mathrm{C}$ over a testing duration of $t=3 \mathrm{~h}$. The highest $T_{o}$ (see Fig. 8a) was obtained with Zeolite $13 \mathrm{X}$ $\left(50{ }^{\circ} \mathrm{C}\right)$. The sorbents were charged at $85^{\circ} \mathrm{C}$ and second discharge cycles performed. There were substantial drops in the Zeolite 13X, SIM-3m and SIM-3ml, whilst SIM-3a and SIM-3cl performed steadily in the repeated cycles. This outcome demonstrates that the SIM-3a and SIM-3cl are effectively regenerated at $85^{\circ} \mathrm{C}$, whereas the rest of the materials require higher temperatures to desorb the moisture.

\subsection{Material hygrothermal performance under low air humidity operating conditions}

In order to assess the hygrothermal performance of the materials at low (inlet air) humidity conditions, a single cycle test at $R H_{i}=60 \%$ and $T_{i}=17^{\circ} \mathrm{C}$ corresponding to $P_{v}=11.6 \mathrm{mbar}$ was performed. The results were compared with the material/system experimental performance at high (inlet air) humidity conditions presented in the previous section. Due to the lower rate of moisture supply, the discharge duration was increased to $t=240 \mathrm{mins}$ in order to keep the moisture uptake of the material the same in both tests. The charging temperature was also reduced from $85^{\circ} \mathrm{C} \rightarrow 72{ }^{\circ} \mathrm{C}$ to investigate the material charging potential at a lower temperature range. As can be seen from Fig. 9a-c, the performance of Zeolite 13X, SIM-3m and SIM-3ml dropped considerably with the reduction in air moisture level, whilst there was a lower effect on the SIM-3a performance. The average temperature lift obtained in SIM-3cl was in close approximation $\left(\Delta T \sim 23^{\circ} \mathrm{C}\right)$ with the high humidity test. This outcome indicates the effect of introducing the $\mathrm{LiCl}$ on increasing the water adsorption capacity at lower humidity levels. $\mathrm{LiCl}$ is highly hygroscopic with a critical $\mathrm{RH}=11.3 \%$ at $25^{\circ} \mathrm{C}$ therefore it could significantly increase both the sorption rate and THS

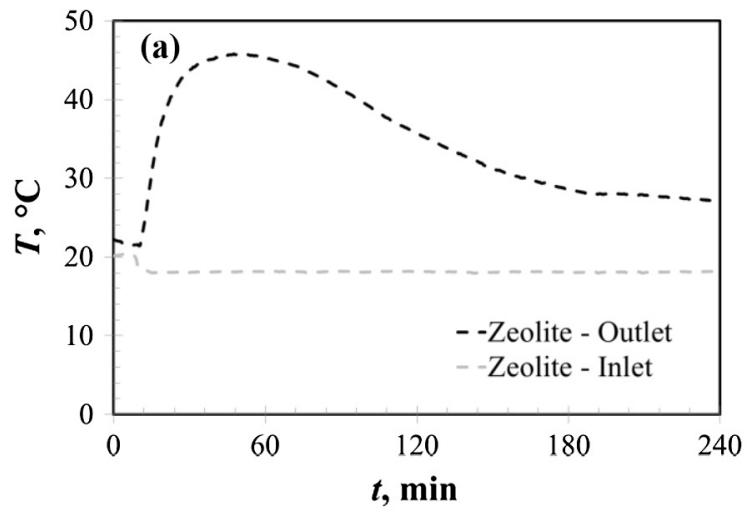

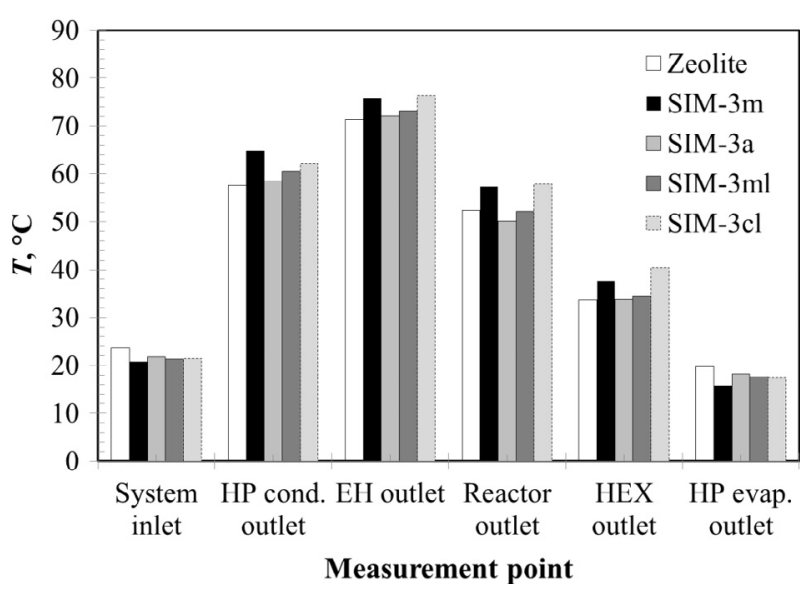

Fig. 10. Temperature variation across system components during charging cycle.

hygrothermal performance under low humidity operating conditions.

In Fig. 10 the average air temperatures at the outlet of each system component are provided. Air enters the system at $\sim 20^{\circ} \mathrm{C}$ and is heated to $\sim 60^{\circ} \mathrm{C}$ in the heat pump condenser where its temperature is boosted to $\sim 75^{\circ} \mathrm{C}$ with the auxiliary electric heater. The reactor outlet temperature was $55-60{ }^{\circ} \mathrm{C}$. Later the air is cooled to $35-40{ }^{\circ} \mathrm{C}$ whilst heat is transferred to a secondary air stream. Finally air enters the HP evaporator and transfers heat to the refrigerant and leaves the system at $\sim 20^{\circ} \mathrm{C}$. During this process, as the air is cooled below dew point, moisture inside the air is condensed and the additional heat recovery is obtained.

\subsection{Evaluation of the overall experimental results}

In this section, the average discharging and charging performance parameters and overall cycle effectiveness related with sorption/

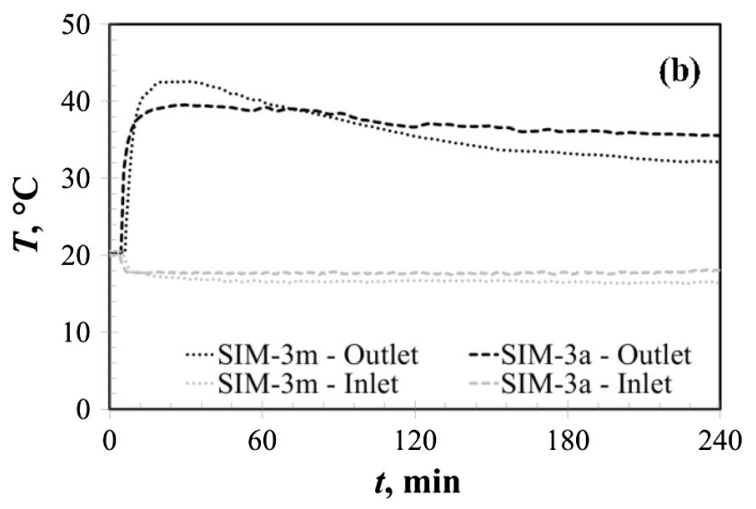

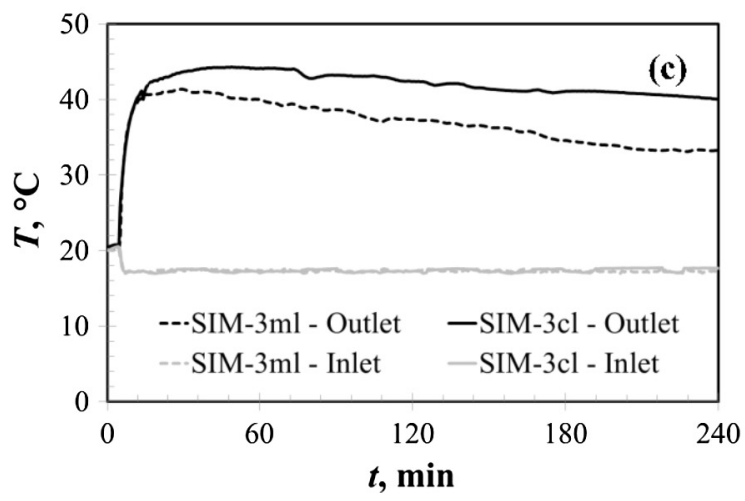

Fig. 9. Measured temperature variation of air across the sorption bed in discharging (left) and charging (right) cycles of different sorbents under low humidity conditions. 
desorption kinetics for full cyclic testing of each material are presented. The summary of discharging, charging and full cycle results of high and low humidity testing are given in Table $2 \mathrm{a}-\mathrm{c}$ and Table $3 \mathrm{a}-\mathrm{c}$ respectively. The key results are also comparatively presented in Figs. 11-13. The following measures are used:

- Initial dry mass of sorbent before discharging, $m_{d i}$,

- Wet mass of sorbent after discharging, $m_{w}$,

- Final mass of sorbent after charging, $m_{d f \text {; }}$

- Ratio of mass uptake $\left(m_{w-} m_{i, d}\right)$ to initial dry mass $\left(m_{i, d}\right)$ of sorbent, $f_{\text {ads }}$

- Ratio of the amount of moisture desorbed $\left(m_{w-} m_{f, d}\right)$ to the wet mass $\left(m_{w}\right)$ of sorbent, $f_{\text {des }}$.

The hygrocyclic efficiency ( $\eta_{\text {hyg-cyc }}$ ) is a key parameter and is defined as the ratio of total moisture desorbed during charging to the total moisture loaded on the sorbent under discharging. The condition $\eta_{\text {hyg- }}$ $c y c=1$ indicates that the final mass of sorbent is equal to its initial mass, which is a priority target in THS systems for effective cyclic use of the sorbents.

SIM-3a and SIM-3cl provided the most promising results among the five sorbents tested. As can be seen from the Table $2 \mathrm{c}, \eta_{\text {hyg-cyc }}$ was found as 0.88 for the high humidity cycles of these sorbents for the $t_{c}=t_{d}$ condition. Although the target was to achieve $\eta_{\text {hyg-cyc }}=1$, there are several factors that can negatively influence the desorption rate resulting in the lower $\eta_{\text {hyg-cyc }}$. These include the limitation of heat and mass transfer due to wetting which reduces permeability and thermal conductivity of the sorbent during discharging. The experiments were also performed in a closed environment (laboratory conditions), therefore moist air from the system is directly exhausted to the room. This resulted in an increased moisture level in the rigs immediate surroundings and thus higher absolute humidity of charging inlet air. This aspect reduced the desorption rate due to the limitation of air moisture uptake capacity.

For SIM-3m, $\eta_{\text {hyg-cyc }}$ was found to be 0.67 and 0.79 for SIM-3ml for the high humidity cycles (see Table $2 \mathrm{c}$ ). This outcome clearly indicates that $\mathrm{LiCl}$ enhances the moisture desorption capacity of the salt $\mathrm{MgCl}_{2}$. For Zeolite $13 \mathrm{X}, \eta_{\text {hyg-cyc }}$ was found as 0.5 which concurs with the high $T_{\text {reg }}$ requirement for charging this sorbent.

In Fig. $11 \mathrm{a}$ and b, $E_{i, t}$ and $E_{o, t}$ the full cycle testing of materials under low and high humidity conditions are comparatively presented. $E_{o, t}$ is the sum of total sorption energy gained in the discharging process and heat recovered with the HEX (See Table $2 b$ and $3 b$ ) in the charging process $\left(E_{H E X}\right)$. As can be seen from Fig. 11a, SIM-3m provided $E_{o, t}=2.88 \mathrm{kWh}$, which was the highest among all the materials tested under the high humidity conditions. $E_{o, t}$ varied in the range of $2.15 \rightarrow$ $2.60 \mathrm{kWh}$ for the other sorbents. In the same tests, the highest $m_{a d s, w}$ was achieved using the Zeolite $13 \mathrm{X}(2.49 \mathrm{~kg})$ whilst $m_{a d s, w}$ was in the range of $1.86 \rightarrow 2.17 \mathrm{~kg}$ for the other materials (see Fig. 12b). SIM-3cl provided the lowest sorption capacity $\left(m_{a d s, w}=1.86 \mathrm{~kg}\right)$ and also the lowest $E_{o, t}$. Contrarily, under the low humidity conditions, total mass uptake and average moisture adsorption rates $\left(Z_{\text {ads,ave }}\right)$ were found to be highest in SIM-3cl which were $0.37 \mathrm{~g} \mathrm{wv}_{\mathrm{wv}} / \mathrm{g}_{\text {ads }}$ and $0.15 \mathrm{gr} / \mathrm{s}$ respectively. Whilst $Z_{\text {ads,ave }}$ for SIM-3a, SIM-3m, SIM-3ml and Zeolite 13X dropped by $30 \%, 35 \%, 37 \%$ and $44 \%$ respectively with the lower humidity level, $Z_{\text {ads,ave }}$ for SIM-3cl reduced by only $12 \%$, making it favourable under low humidity operating conditions. Accordingly $E_{o, t}$ of SIM-3cl increased from $2.15 \mathrm{kWh}$ to $2.61 \mathrm{kWh}$ at higher humidity. $E_{o, t}$ for all the other materials showed a decreasing trend using the reduced humidity level. Similarly $m_{a b s, w}$ increased from $1.86 \mathrm{~kg}$ to $2.12 \mathrm{~kg}$ in SIM-3cl testing, whilst the rest of the sorbents showed a lower sorption capacity that led to poor hygrothermal performance.

The total energy input for the full cycle test was calculated as the sum of the compressor, electrical heater, fan and humidifier energy consumption based on experimental data. It was found that the highest total energy input $\left(E_{i, t}\right)$ was supplied by Zeolite $13 \mathrm{X}(2.30 \mathrm{kWh})$ under the high humidity cycle $\left(T_{c}=85^{\circ} \mathrm{C}\right)$. This mainly occurred as a result of the zeolite's high desorption enthalpy and high specific heat increasing the amount of energy required for moisture extraction. In the charging cycle for Zeolite $13 \mathrm{X}$ (at $T_{\text {reg }}=72{ }^{\circ} \mathrm{C}$ ), $E_{i, t}$ dropped from $2.30 \mathrm{kWh}$ to $1.18 \mathrm{kWh}$. SIM-3cl provided the highest $f_{\text {ads }}$ under the low humidity cycles. Due to its high moisture content, SIM-3cl adsorbed a large

Table 2

Summary of the testing results of different sorbents at high humidity levels; (a) discharging cycle, (b) charging cycle (c) full cycle.

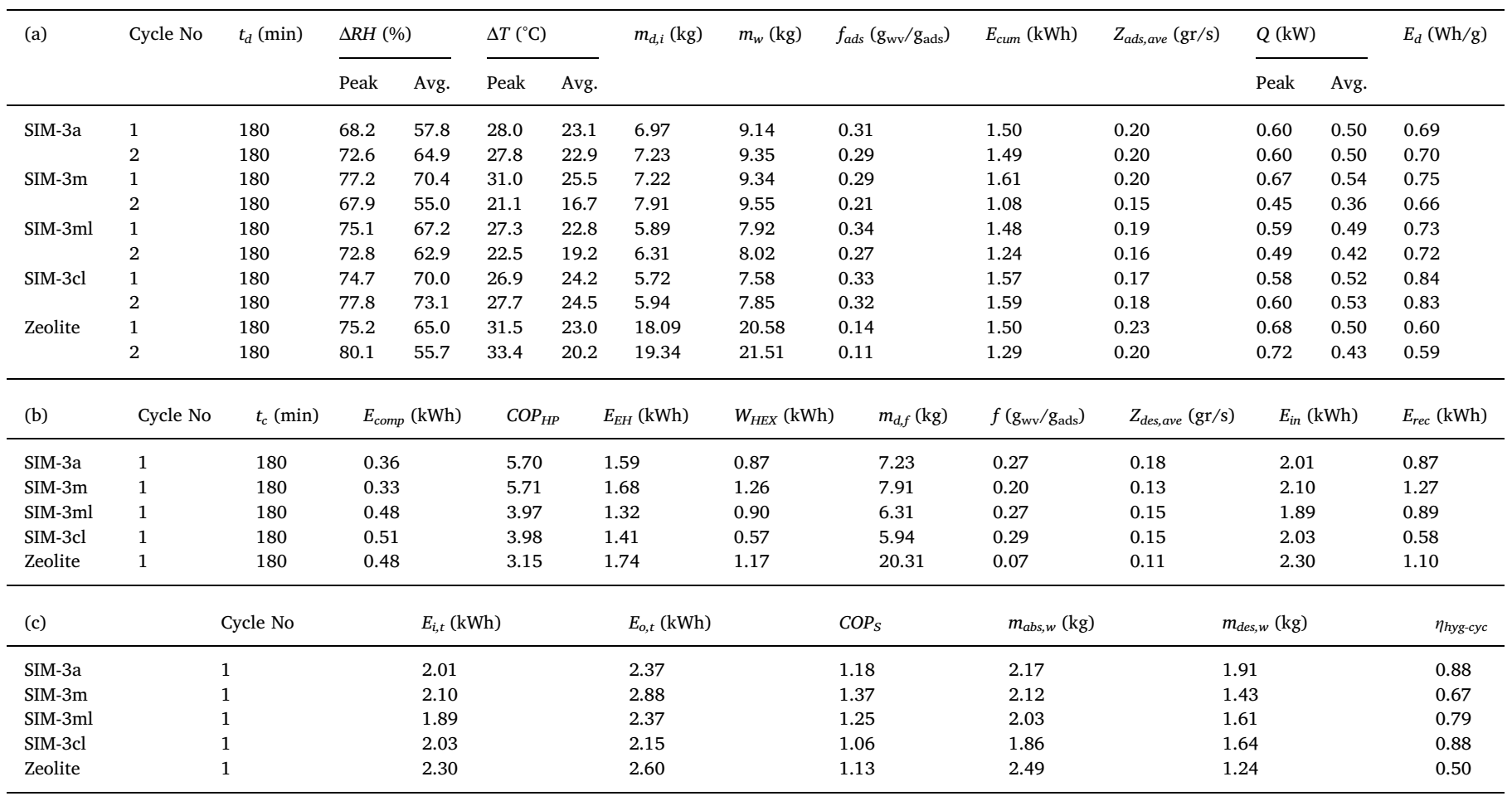


Table 3

Summary of the testing results of different sorbents at low humidity levels; (a) discharging cycle, (b) charging cycle (c) full cycle.

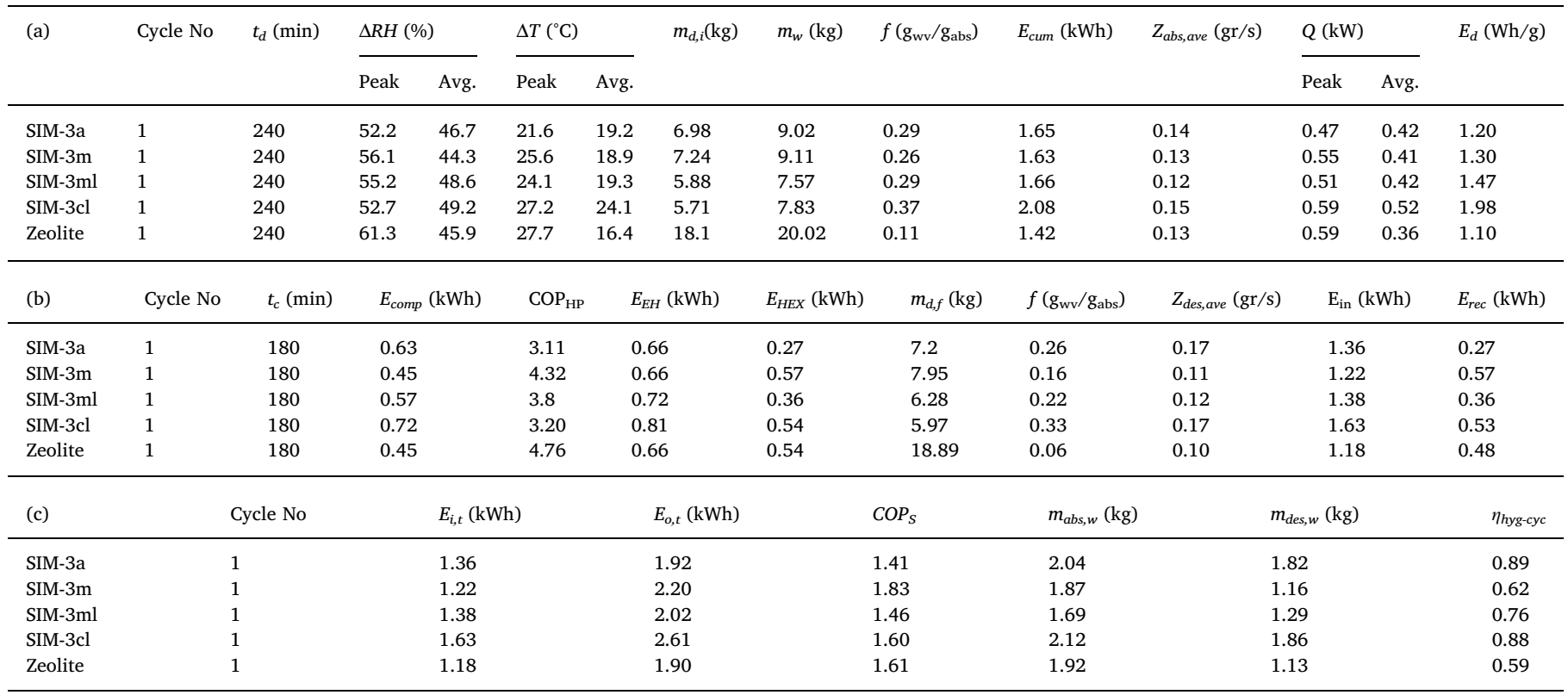

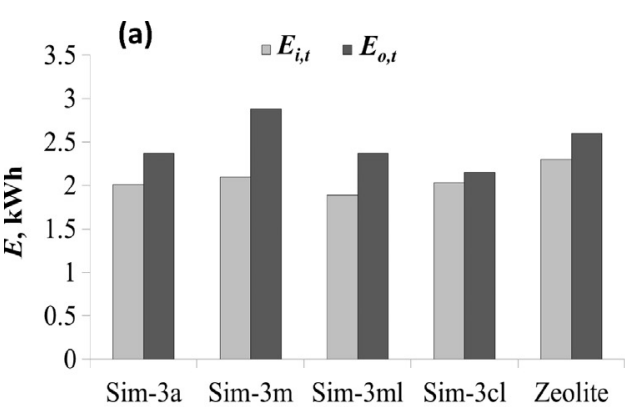

Sorption material
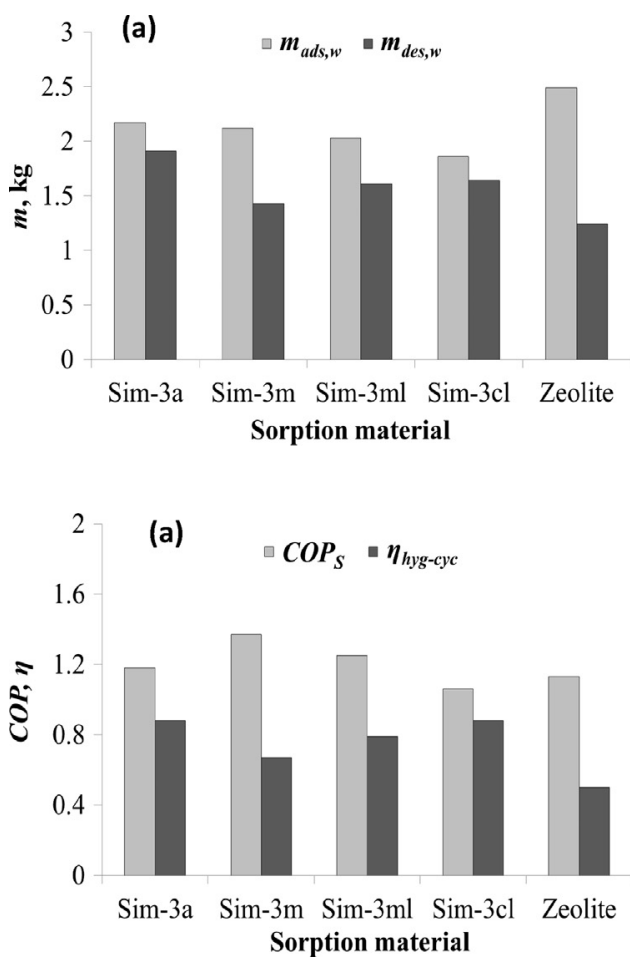

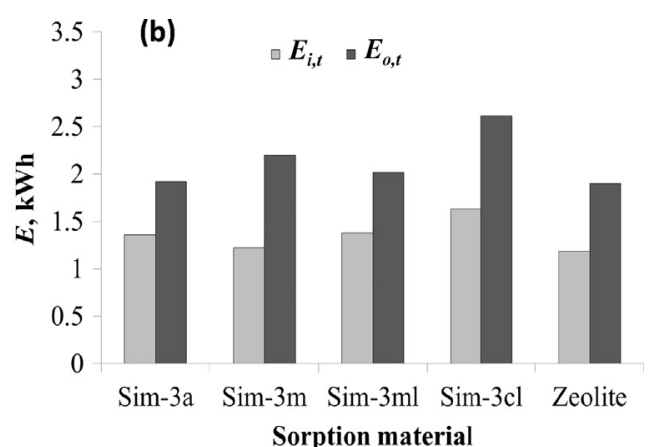

Fig. 11. (a) Total energy input-output in testing of different sorbents at (a) high (b) low humidity conditions.

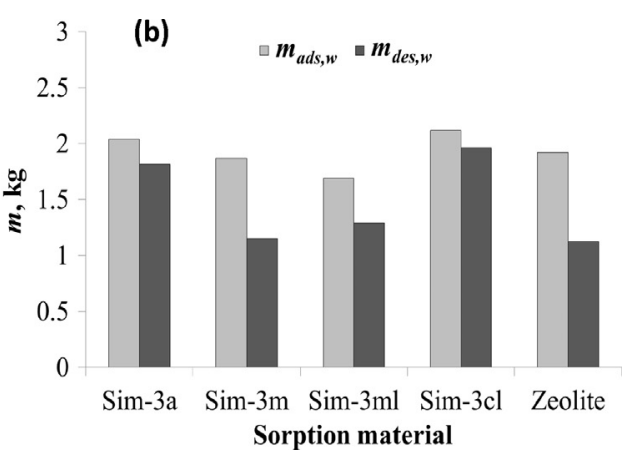

(b) $\quad C O P_{S} \backsim \eta_{h y g-c y c}$

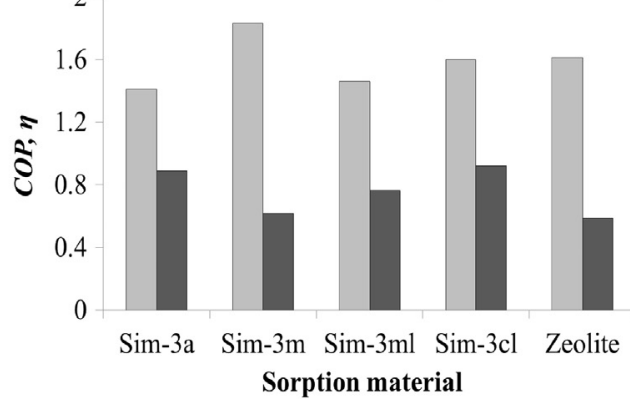

Fig. 12. (a) Amount of absorbed-desorbed moisture in testing of different sorbents at (a) high (b) low humidity conditions.
Fig. 13. (a) $C O P_{S}$ and $\eta_{\text {hyg-cyc }}$ in testing of different sorbents at (a) high (b) low humidity conditions. 
amount of input heat thereby there was a lower amount of waste heat recovered in the evaporator resulting in higher energy consumption of the compressor and electrical heater. $E_{i, t}$ was highest in SIM-3cl under charging at $T_{r e g}=72{ }^{\circ} \mathrm{C}$ whilst $E_{i, t}$ for the other materials tested were $1.38 \mathrm{kWh}$ (SIM-3ml), $1.36 \mathrm{kWh}$ (SIM-3a), $1.22 \mathrm{kWh} \mathrm{(SIM-3m),} \mathrm{and}$ $1.18 \mathrm{kWh}$ (Zeolite $13 \mathrm{X}$ ) at the same $T_{\text {reg. }}$.

Based on the data obtained for the full cycle tests the overall system $\mathrm{COP}_{s}$ was calculated using the equation below:

$C O P_{s}=\frac{\int_{0}^{t_{d}} Q_{d c h r} d t+\int_{0}^{t_{c}} Q_{H E X} d t}{\int_{0}^{t_{c}}\left(W_{\text {comp }}+W_{E H}+W_{f a n}\right) d t+\int_{0}^{t_{d}}\left(W_{\text {hum }}+W_{f a n}\right) d t}$

By integrating the terms in Eq. (38) for the charging $\left(t_{c}\right)$ and discharging $\left(t_{d}\right)$ durations, Eq. (39) for $\mathrm{COP}_{s}$ was obtained as follows:

$C O P_{s}=\frac{E_{\text {dchr }}+E_{H E X}}{E_{\text {comp }}+E_{E H}+E_{f a n}+E_{\text {hum }}}$

where $E_{d c h r}$ is the total energy output in the discharging process, $E_{H E X}$ is the total energy recovered in the heat exchanger during the charging process, $E_{\text {comp }}$ is the energy consumption of the heat pump compressor, $E_{E H}$ is the energy consumption of the electrical heater, $E_{f a n}$ is the energy consumption of the fan and the $E_{\text {hum }}$ is the energy consumption of the ultrasonic humidifier.

The overall system COP's are presented in Fig. 13a and b. The $C O P_{S}$ of the heat storage processes using SIM- $3 \mathrm{~m}$ and SIM- $3 \mathrm{ml}$ were found to be the two highest with 1.37 and 1.25 respectively, where $C O P_{S}$ of SIM3a, Zeolite $13 \mathrm{X}$ and SIM-3m were in the order of $1.18,1.13$ and 1.06 for the 1 st high humidity discharging cycle. In the second testing phase under low humidity discharging and low $T_{\text {reg }}\left(72{ }^{\circ} \mathrm{C}\right)$, the $C O P_{S}$ of the heat storage process for all materials substantially increased due to the lower energy consumption of the electrical heater. SIM-3m was again found to be the sorbent providing the highest COP of 1.83. Zeolite $13 \mathrm{X}$ and SIM-3cl were in close approximation with the COP values of 1.61 and 1.60 respectively (Fig. 13b). Due to their poor hygrothermal performance under low humidity discharging conditions, the $C O P_{S}$ values were lower for SIM-3ml (1.46) and SIM-3a (1.41).

\subsection{Long cycle performance}

In this section the long-term performance of the heat pump driven sorption storage heater was investigated. SIM-3a was selected as the primary sorption material due to the promising results obtained with this material in previous section (Section 3). Although SIM-3cl also provided an improved performance, SIM-3a was preferred because of its better known characteristics, lower cost and less corrosive nature.

Two long cycle tests were performed with SIM-3a consisting of a $1200 \mathrm{~min}$ discharge, a $360 \mathrm{~min}$ charge and a $960 \mathrm{~min}$. discharge. As the previous section investigated multiple materials in the developed system, short cycles were performed to compare their performances for

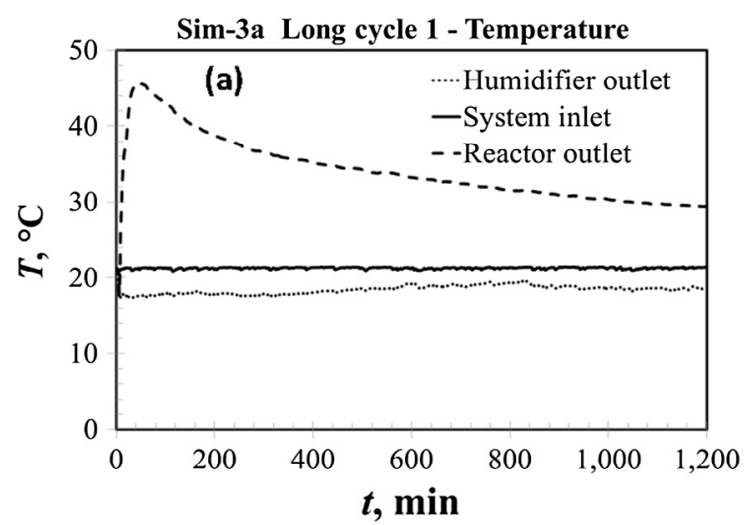

the operation of equal time frames. In this part, the overall performance of SIM-3a was investigated. In the first discharging cycle, $T_{o}$ reached $45^{\circ} \mathrm{C}$ (See Fig. 14a) and $\Delta T / \Delta t$ was found to be $0.0125^{\circ} \mathrm{C} / \mathrm{min}$, showing the steady performance of SIM-3a. At the same time $R H_{o}$ varied in range of $11 \rightarrow 50 \%$ whilst $R H_{i}$ fluctuated between 70 and $80 \%$. The thermal power output, $Q_{t}$, varied in the range of $0.6-0.22 \mathrm{~kW}$ whilst $E_{o}$ was $6.77 \mathrm{kWh}$ at the end of the 1200 min discharging period (see Fig. 14b). Following the discharging period, the material was regenerated at $T_{\text {reg, }}$ ave $=85^{\circ} \mathrm{C}$ (see Fig. 15a and b). For the charging process, the total electric energy input to the system was calculated as $3.23 \mathrm{kWh}$ where $0.96 \mathrm{kWh}$ of it was thermally recovered using the HEX.

Based on the total energy input-output in both the charging and discharging processes, the $C O P_{S}$ was calculated as 2.39. This $C O P_{S}$ was substantially higher than that recorded for the short cycle test for SIM3a where the lower operating time limited the heat output extracted from the material, significantly reducing the $C O P_{S}$.

After charging the material, the second discharging cycle was performed (See: Fig. 16a and b). Over $t=960 \mathrm{~min}$ discharging $T_{o}$ varied in the range of $45 \rightarrow 30^{\circ} \mathrm{C}$, corresponding to a $\Delta T / \Delta t=0.0156^{\circ} \mathrm{C} / \mathrm{min}$. which was higher than the initial cycle. The higher $\Delta T / \Delta t$ indicates the faster drop in temperature lift, $\Delta T$, which is undesirable. This most likely occurred as a result of residual moisture remaining inside the material. The results showed that $0.61 \mathrm{~kg}$ of the loaded $6.54 \mathrm{~kg}$ moisture remained inside the material after charging. This corresponds to a $\eta_{\text {hyg-cyc }}=91 \%$ showing that the regeneration of the material was very efficient. Further development could be focused on improving the reactor design to enhance the heat and mass transfer during charging.

\section{Numerical analysis of heat-store system}

A schematic diagram illustrating the charging and discharging system operation was presented with the assigned flow numbers in Fig. 3a and b respectively (see Section 3.2). The description of the flow numbers were also illustrated in Table 1 . The system consists of a fan, ultrasonic humidifier, sorption reactor, attic HP, auxiliary electrical heater and an air-to-air heat exchanger. Solar air collectors could also be optionally used at the system inlet to preheat the air before entering the HP.

The full cycle of the system consists of charging $(1 \rightarrow 6)$ and discharging $(9 \rightarrow 11)$ cycles.

During charging, the primary aim is to achieve an energy efficient drying cycle of sorbent that benefits from ambient energy and system exhaust waste heat. This cycle includes a two stage heat recovery where the moist air leaving the sorption reactor (4) transfers some of the energy to an external air flow $(7 \rightarrow 8)$ via an air to air heat exchanger whilst the rest of its energy is recovered via the HP. This condition both increases the $\mathrm{COP}_{H P}$ whilst gaining useful heat for space heating. In the charging cycle, ambient air could be pre-heated using transpired solar collectors (optional). The inlet air (1) enters the condenser and is

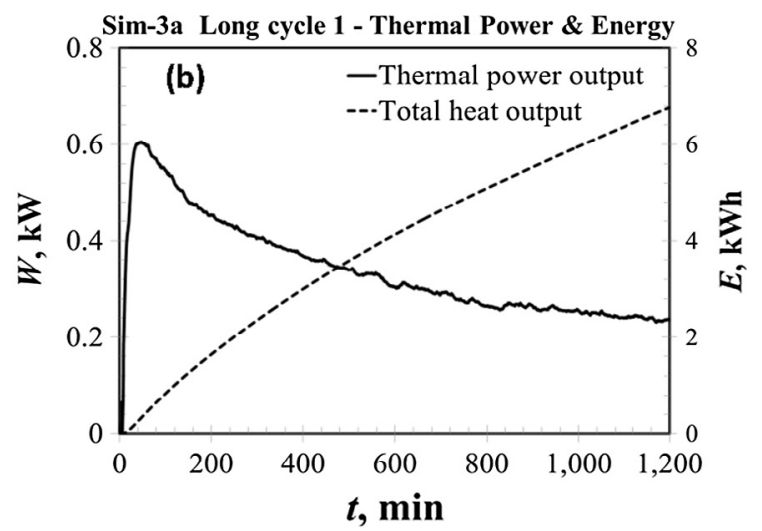

Fig. 14. Measured (a) temperatures and (b) relative humidites in 1 st long discharging cycle of SIM-3a. 

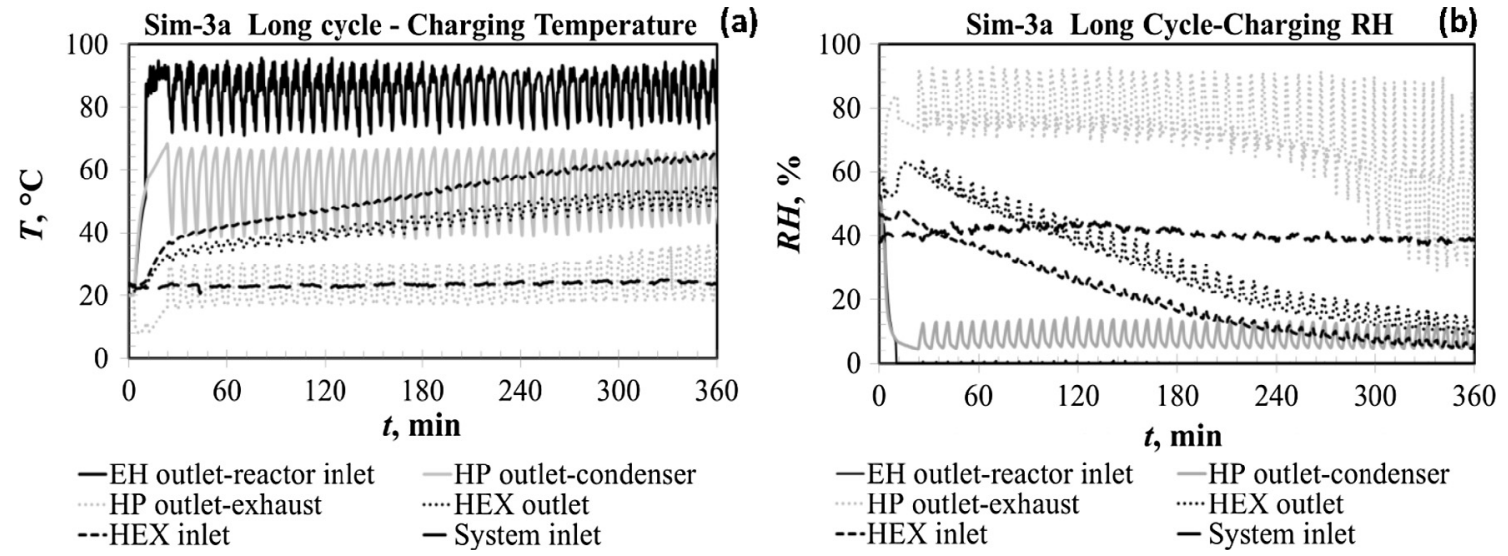

- HP outlet-condenser

…. HEX outlet

-.HEX inlet - System inlet (a)

Fig. 15. Measured (a) temperatures and (b) relative humidites in long charging cycle of SIM-3a.
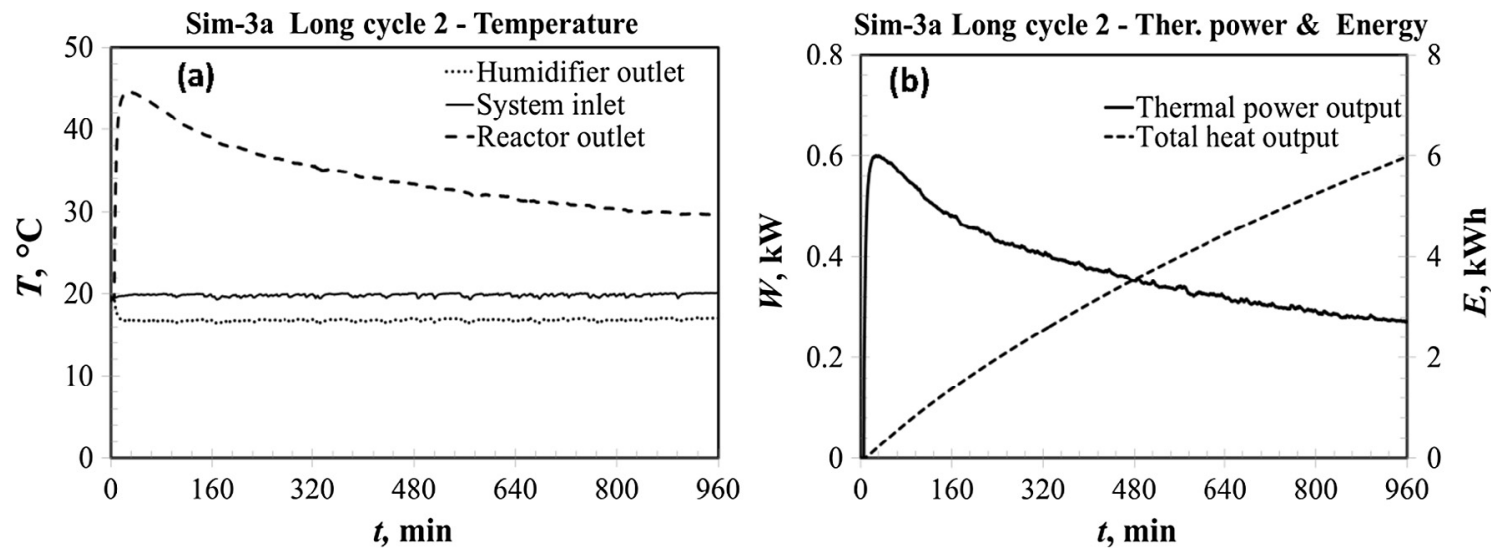

Fig. 16. Measured (a) temperatures and (b) relative humidites in 2nd long discharging cycle of SIM-3a.

heated up to $50-60{ }^{\circ} \mathrm{C}(2)$. The temperature of the air is then boosted with an electrical heater (3). Hot air passes through the sorbent and leaves the sorption reactor with increased moisture content (4). Moist warm air transfers sensible heat to an external line with a heat exchanger (5). The output air from the heat exchanger is close to saturation. Finally, it passes through the evaporator where it reaches to the saturation point and some of the moisture condenses. As a result, condensation energy is transferred to the refrigerant which considerably reduces the compressor energy consumption. Air leaving the evaporator is exhausted to the ambient (6). In discharging cycle, the inlet air (9) passes through the humidifier and its moisture content increases. The moist inlet air (10) then enters the sorption reactor where it is heated as a result of moisture sorption by the sorbent. Hot/ dry output air (11) finally leaves the system to be used for heating.

\subsection{Numerical model}

In the numerical analysis, the effect of different parameters including the air temperature, humidity, mass flow rate and solar energy input on system performance were investigated. Whilst simulating the effect of any one parameter, the rest of the conditions, which were not a function of the simulated parameter, were kept constant.

SIM-3a was selected as the sorption material to be used in the analyses. The physical properties of SIM-3a and other constants used in the model are presented in Table 4.

Engineering Equation Solver (EES) V9.933-3D was used to perform the simulations. With EES, it is possible to simulate timewise variations of several parameters during the sorption storage heater charging and discharging processes. EES software also allows for the investigation of the effects of multiple variables on any target function (e.g. COPs). The investigated parameters are given in the flowchart below (see Fig. 17). Collector area $\left(A_{\text {coll }}\right)$, solar intensity $(I)$, charging temperature $\left(T_{3}\right)$, air mass flow rate $\left(m_{a}\right)$ and discharging air inlet temperature $\left(T_{10}\right)$ were used as variables. Based on the temporal variation of each of these variables, the change of system performance indicators such as system total energy input-output in charging and discharging processes, $C O P_{H P}$ and overall system $\mathrm{COP}\left(\mathrm{COP}_{S}\right)$ were investigated.

Table 4

Constants and assumptions used in the analysis.

\begin{tabular}{lll}
\hline Parameter & Value & Unit \\
\hline$V_{a b s}\left(V-\mathrm{CaCl}_{2}\right)$ & 0.05 & $\mathrm{~m}^{3}$ \\
$\rho_{a b s}$ & 175 & $\mathrm{~kg} / \mathrm{m}^{3}$ \\
$m_{a b s}$ & 8.75 & $\mathrm{~kg}$ \\
Porosity & 65 & $\%$ \\
$t_{d}$ & 600 & minutes \\
$W_{\text {fan }}$ & 0.05 & $\mathrm{~kW}$ \\
$W_{\text {hum }}$ & 0.03 & $\mathrm{~kW}$ \\
$T_{i, c}\left(T_{1}\right)$ & 15 & ${ }^{\circ} \mathrm{C}$ \\
$R H_{i, c}\left(R H_{1}\right)$ & 30 & $\%$ \\
$m_{a}$ & 0.02 & $\mathrm{~kg} / \mathrm{s}$ \\
$m_{a, H E X} H$ & $\mathrm{~kg} / \mathrm{s}$ \\
$T_{i, d}\left(T_{9}\right)$ & 0.005 & ${ }^{\circ} \mathrm{C}$ \\
$T_{c}\left(T_{3}\right)$ & 15 & ${ }^{\circ} \mathrm{C}$ \\
$R H_{i, d}\left(R H_{9}\right)$ & 85 & $\%$ \\
$\Delta h_{w}$ & 30 & $\mathrm{~kJ} / \mathrm{kg}$ water \\
$C p_{w}$ & 435.1 & $\mathrm{~kJ} / \mathrm{kg} \mathrm{K}$ \\
$C p_{a}$ & 4.18 & $\mathrm{~kJ} / \mathrm{kg} \mathrm{K}$ \\
$M_{m, w}$ & 1.008 & $\mathrm{~kg} / \mathrm{mol}$ \\
\hline
\end{tabular}




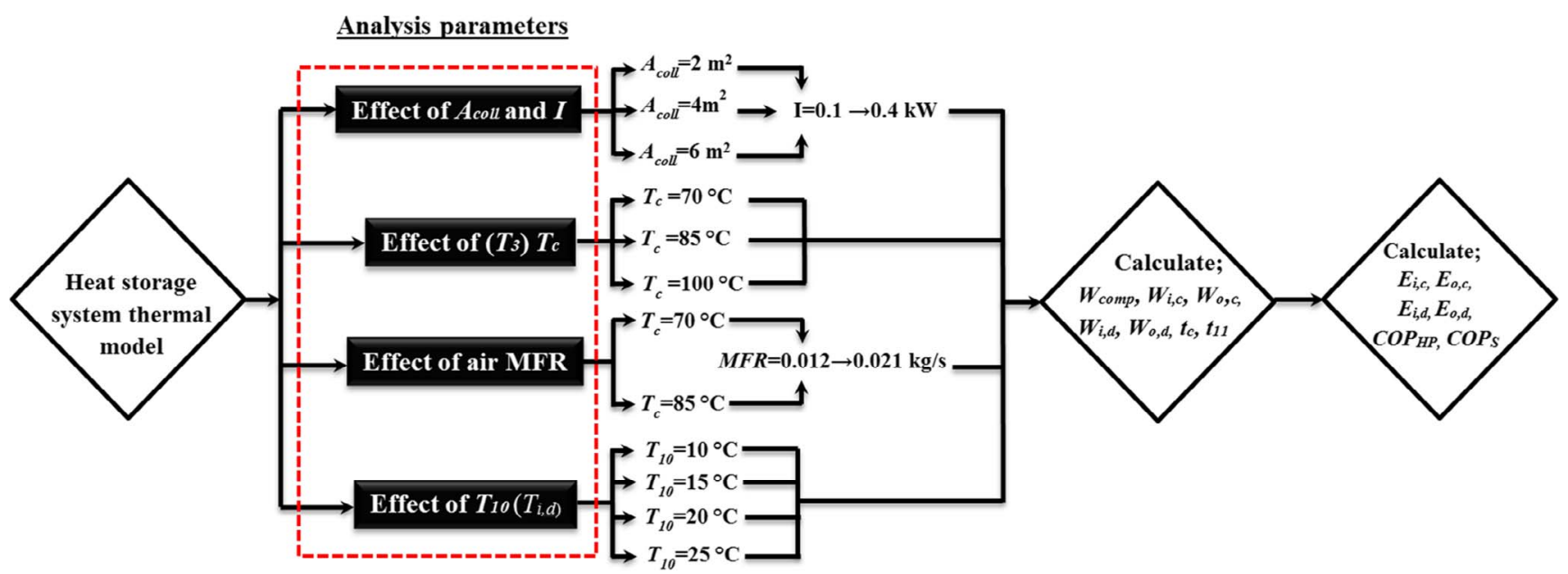

Fig. 17. Flow chart of numerical model illustrating the investigated parameters.

\subsection{Results and discussion}

\subsubsection{Effect of solar energy input}

Despite no solar unit being used in the proposed experimental system, it is aimed to investigate the effect of the solar energy input on system performance through numerical analysis. A solar air heater with a surface area $\left(A_{\text {coll }}\right)$ varying between of $2 \rightarrow 6 \mathrm{~m}^{2}$ was integrated at the system inlet to preheat the air before entering the heat pump condenser unit. Simulations were performed for solar radiation $(I)$ levels in the range of $0.1 \rightarrow 0.4 \mathrm{~kW} / \mathrm{m}^{2}$. The aim was to analyse the reduction of $\mathrm{HP}$ energy consumption with the increasing solar energy input during the sorbent regeneration process. The drop of compressor power requirement boosts $C O P_{H P}$ thereby increasing overall system $\mathrm{COP}\left(C O P_{S}\right)$. The variation of $T_{1}$ (heat pump inlet temperature) depending on $A_{\text {coll }}$ and $I$ levels is given in Fig. 18. As seen $T_{1}$ linearly rises with the increasing $A_{\text {coll }}$ and $I$. The impact of the $A_{\text {coll }}$ is minor at low $I$ levels however it becomes significant with increasing $I$. The effect of $A_{\text {coll }}$ and $I$ on system performance is investigated in detail in the following section.

Based on the analysis results, for $A_{\text {coll }}=2 \mathrm{~m}^{2}$, each $0.1 \mathrm{~kW}$ input of solar energy provides approximately the same amount of reduction of $W_{\text {comp. }}$. A fourfold increase of $I\left(0.1 \mathrm{~kW} / \mathrm{m}^{2} \rightarrow 0.4 \mathrm{~kW} / \mathrm{m}^{2}\right)$, results in a drop of average $W_{\text {comp }}$ from $0.65 \mathrm{~kW}$ to $0.32 \mathrm{~kW}$. Accordingly, $C O P_{H P \text {, ave }}$ was found to be 2.95 for $I=0.4 \mathrm{~kW}$ whereas it was 1.93 for $I=0.1 \mathrm{~kW} /$ $\mathrm{m}^{2}$ (see: Fig. 19). With an increase in the $C O P_{H P}, C O P_{S}$ increases in the range of $1.41 \rightarrow 2.69$ as can be seen in Fig. 19. Based on the varying $I$, the average $C O P_{s}$ is 2.7 for $I=0.4 \mathrm{~kW} / \mathrm{m}^{2}$ and 1.4 for $I=0.1 \mathrm{~kW} / \mathrm{m}^{2}$ (see: Fig. 19). The reason for the sharp decrease in $C O P_{s}$ could be explained with the increase in total $E_{i, c}$ from $1.6 \mathrm{kWh}$ to $3.1 \mathrm{kWh}$ for reducing $I$ in the range of $0.4 \rightarrow 0.1 \mathrm{~kW}$. As the $E_{o, d}, E_{o, c}, E_{i, d}$ are steady (3.1, 1.4 and $0.3 \mathrm{kWh}$ respectively) for the varying $I$ levels, the increase of $E_{i, c}$ reduces the $\mathrm{COP}_{s}$.

The increase in solar collector area from $2 \mathrm{~m}^{2}$ to $4 \mathrm{~m}^{2}$ enables a further decrease in HP power consumption. For $I=0.1 \mathrm{~kW} / \mathrm{m}^{2}$, the reduction in $W_{\text {comp }}$ is lower with and average of $0.63 \mathrm{~kW}$. However with increasing $I$ levels, the effect of solar collector area becomes more considerable. For $I=0.4 \mathrm{~kW} / \mathrm{m}^{2}, W_{\text {comp, ave }}$ reduces to $0.2 \mathrm{~kW}$. The significant reduction of $W_{\text {comp }}$, boosts $C O P_{H P}$ and $C O P_{S}$. The results show that $C O P_{H P \text {,ave }}$ and $C O P_{s, \text { ave }}$ are 4.15 and 3.93 respectively for the conditions $I=0.4 \mathrm{~kW} / \mathrm{m}^{2}$ and $A_{\text {coll }}=4 \mathrm{~m}^{2}$ (see Fig. 20) (see Fig. 21).

With the increase of $A_{\text {coll }}$ to $6 \mathrm{~m}^{2}, W_{\text {comp,ave }}$ drops to $0.16 \mathrm{~kW}$, for $I=0.4 \mathrm{~kW} / \mathrm{m}^{2}$. For $I=0.1 \mathrm{~kW} / \mathrm{m}^{2}, W_{\text {comp }}$ is $0.63 \mathrm{~kW}$ which is slightly lower than the achieved $W_{\text {comp }}$ for the $A_{\text {coll }}=2 \mathrm{~m}^{2}$ and $4 \mathrm{~m}^{2}$ under the same $I$ levels. It could be concluded that the increasing solar collector area enables a considerable reduction in $W_{\text {comp }}$ when $I$ in the range of $0.3-0.4 \mathrm{~kW}$, whereas it does not have much impact at lower $I$ levels $\left(0.1-0.2 \mathrm{~kW} / \mathrm{m}^{2}\right) . C O P_{H P \text {, ave }}$ and $C O P_{S \text {, ave }}$ are calculated as 4.62 and
4.34 for $I=0.4 \mathrm{~kW} / \mathrm{m}^{2}$, whilst they are 1.97 and 1.48 for $I=0.1 \mathrm{~kW} \mathrm{~kW} / \mathrm{m}^{2}$ respectively.

Based on the simulations performed integrating solar air collectors to the HP and regenerating the material when solar energy is available seems to be a suitable and energy efficient option. As a result of the solar input to the system, a lower $W_{\text {comp }}$ is required to achieve the desired air temperature for regeneration. This condition increases the $H P_{C O P}$ and overall heat storage performance. The conditions of $A_{\text {coll }}>4 \mathrm{~m}^{2}$ and $I>0.3 \mathrm{~kW}$ was found as the lowest values to achieve a competititive performance with the conventional air sourced HP which generally has an average COP of $\approx 3$. For climate conditions where winter solar intensity is above $0.3 \mathrm{~kW}$, a $\mathrm{COP}_{\mathrm{s}}>3$ could easily be achieved. This condition makes the use of an integrated sorption heat storage and solar assisted heat pump an attractive solution for heat storage based space heating applications. Performing the charging cycles with PV sourced electricity or off peak electricity could also substantially reduce the operating costs.

\subsubsection{Effect of reactor inlet air temperature in discharging cycle}

The temperature of the reactor inlet air $T_{10}\left(T_{i, d}\right)$ discharging process has a vital importance on overall heat storage performance. The change in discharging inlet air temperature not only affects the discharging heat output but also it affects the charging process heat input and output. For the same RH level, the moisture content of the inlet air increases with increasing temperature. As a result, with the increasing $T_{10}$ (e.g. $10^{\circ} \mathrm{C} \rightarrow 25^{\circ} \mathrm{C}$ ) for a steady $R H_{10}$ (e.g. $80 \%$ ), the amount of the moisture loaded to the sorbent increases during adsorption process.

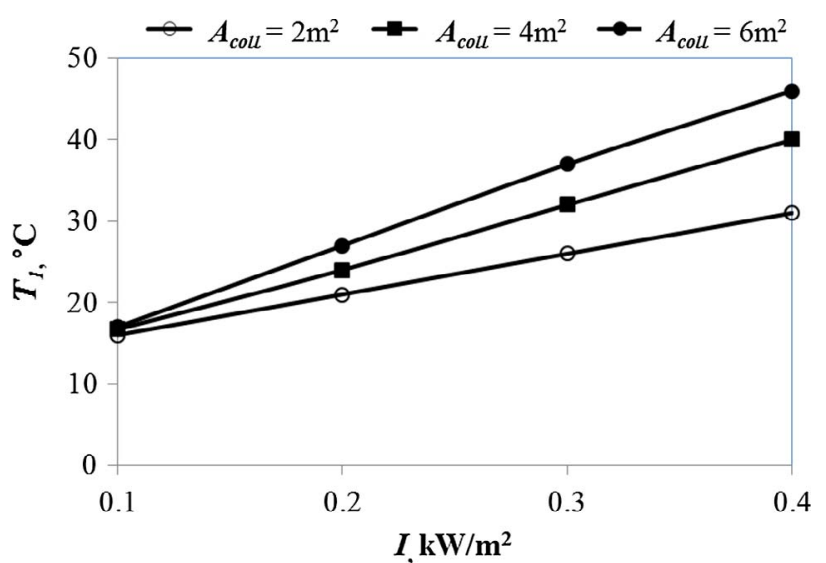

Fig. 18. Variation of charging inlet temperature for different $A_{\text {coll }}$ and solar radiation levels. 


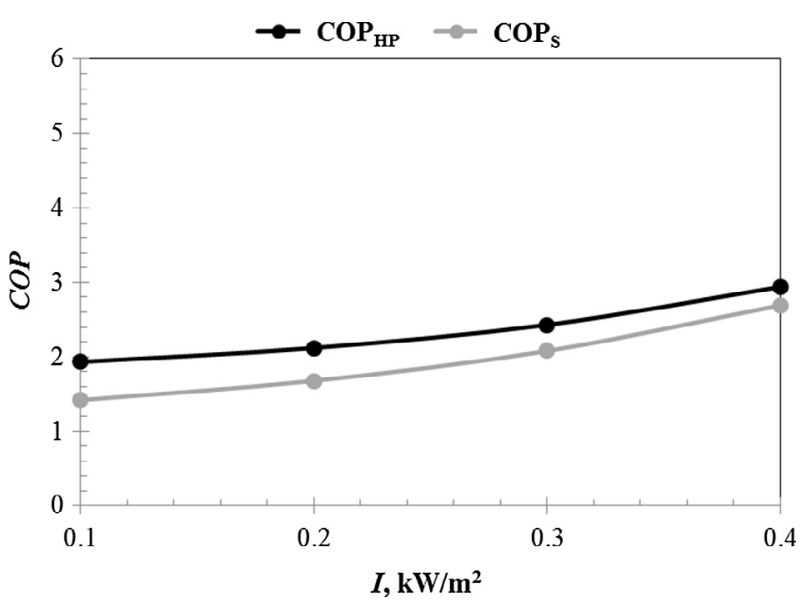

Fig. 19. Effect of solar radiation on (a) $C O P_{H P}$ and (b) $C O P_{S}$ for $A_{\text {coll }}$ of $2 \mathrm{~m}^{2}$.

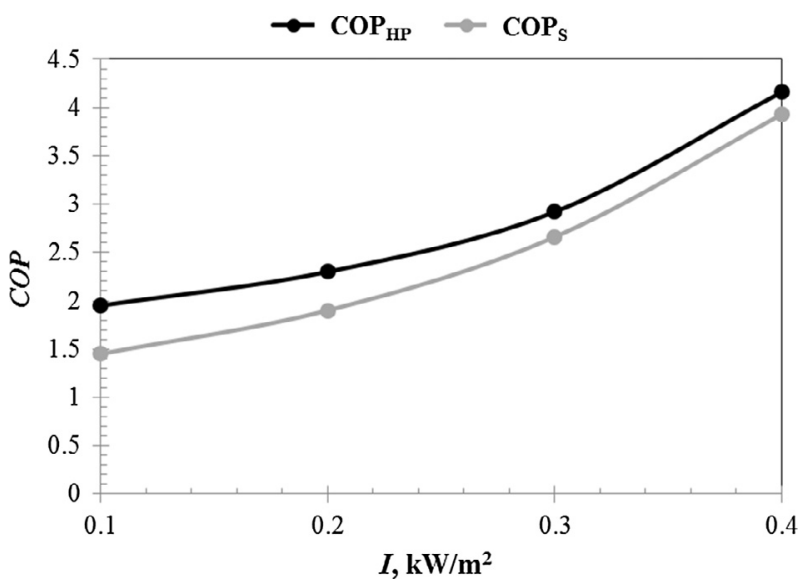

Fig. 20. Effect of solar radiation on (a) $C O P_{H P}$ and (b) $C O P_{S}$ for $A_{\text {coll }}$ of $4 \mathrm{~m}^{2}$.

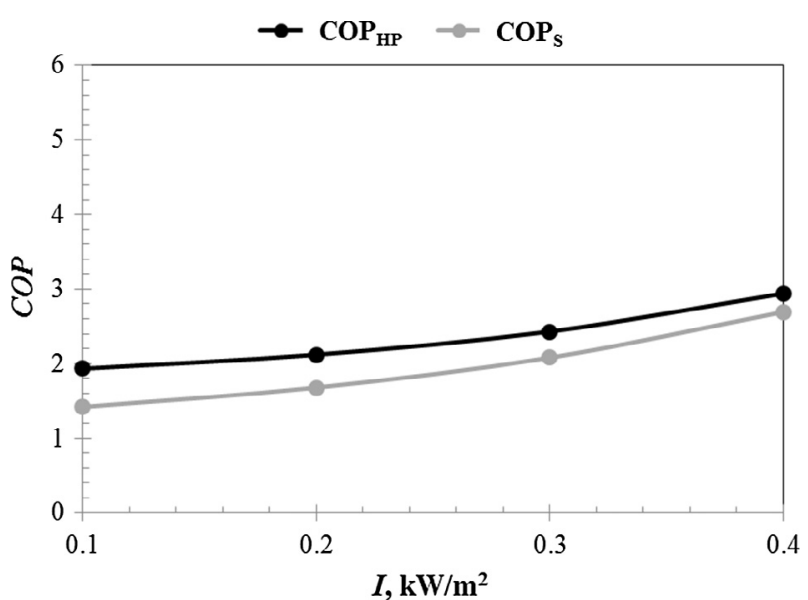

Fig. 21. Effect of solar radiation on (a) $C O P_{H P}$ and (b) $C O P_{S}$ for solar collector area of $6 \mathrm{~m}^{2}$.

Although this leads to higher sorption heat output, it also increases the $t_{c}$, therefore the energy required to regenerate the material. According to the analysis results, $t_{c}$ increases from $132 \mathrm{~min}$ to $482 \mathrm{~min}$ with the rise of the $T_{i, d}$ in the range of $10 \rightarrow 25^{\circ} \mathrm{C}$ for $\mathrm{RH}=80 \%$ conditions. On the other hand peak temperature lift $\Delta T$ is $12^{\circ} \mathrm{C}$ for a $T_{i, d}=10^{\circ} \mathrm{C}$, but a $\Delta T=31^{\circ} \mathrm{C}$ could be achieved for a $T_{i, d}=25^{\circ} \mathrm{C}$. Increasing $T_{i, d}$ from $10 \rightarrow 25^{\circ} \mathrm{C}$ increases $E_{i, c}, E_{o, c}$ and $E_{o, d}$ from $1.01 \rightarrow 4.24 \mathrm{kWh}, 0.68 \rightarrow$ $2.48 \mathrm{kWh}$ and $1.51 \rightarrow 5.10 \mathrm{kWh}$ respectively. As a result, $C O P_{s}$, which takes into account both the input and output energy in both charging

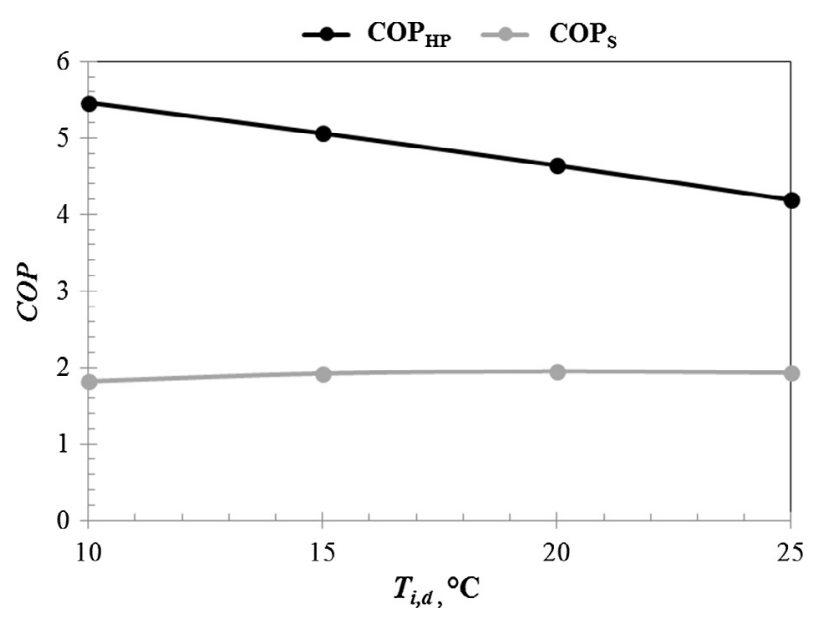

Fig. 22. Effect of charging inlet temperature on $C O P_{H P}$ and $C O P_{S}$.

and discharging cycles, does not show a considerable change $(1.82 \rightarrow$ 1.93) with the varying $T_{i, d}$ (see Fig. 22).

\subsubsection{Effect of charging temperature}

The effect of $T_{c}\left(T_{3}\right)$ on system performance was simulated in this section. In the model, $T_{i, c}$ is considered as $15^{\circ} \mathrm{C}$. Three cases were investigated where $T_{c}$ is set at 70,85 and $100^{\circ} \mathrm{C}$. Although $t_{c}$ drops considerably (274 $\rightarrow 228 \mathrm{~min}$ ) with the increasing $T_{c}$, the energy consumption of both the HP and EH increase. This condition results in an increase of overall energy input to the system. For the increase of $T_{c}$ in the range of $70 \rightarrow 100^{\circ} \mathrm{C}$, total $E_{i, c}$ varies between 2.3 and 4.2 . As a result of the increasing $E_{i, c}, C O P_{H P}$ and $C O P_{S}$ drop in the range of $4.8 \rightarrow$ 2 and $1.9 \rightarrow 1$ respectively (see Fig. 23). With the current available domestic HP technologies, it is highly unlikely to achieve an air temperature $>60{ }^{\circ} \mathrm{C}$. Therefore, an auxiliary EH would be required to boost the air temperature to the required regeneration temperature. Use of the EH significantly increases the energy consumption. Also at high $T_{c}$ levels, energy losses are higher. Moreover, the HP evaporator inlet temperature is higher with an increasing $T_{c}$, thus waste heat could only partially be recovered. As a result of the combined effect of these factors, the overall heat storage performance drops at a higher $T_{c}$. It could thus be concluded that efficient regeneration of the sorbent at low $T_{c}$ is crucial for THS process. This suggests that in future, sorption materials that allow regeneration at $T_{c}<70^{\circ} \mathrm{C}$ need to be sought.

\subsubsection{Effect of mass flow rate}

In this section effect of air mass flow rate $\left(m_{a}\right)$ on the sorption storage heater performance is analysed. Simulations were performed

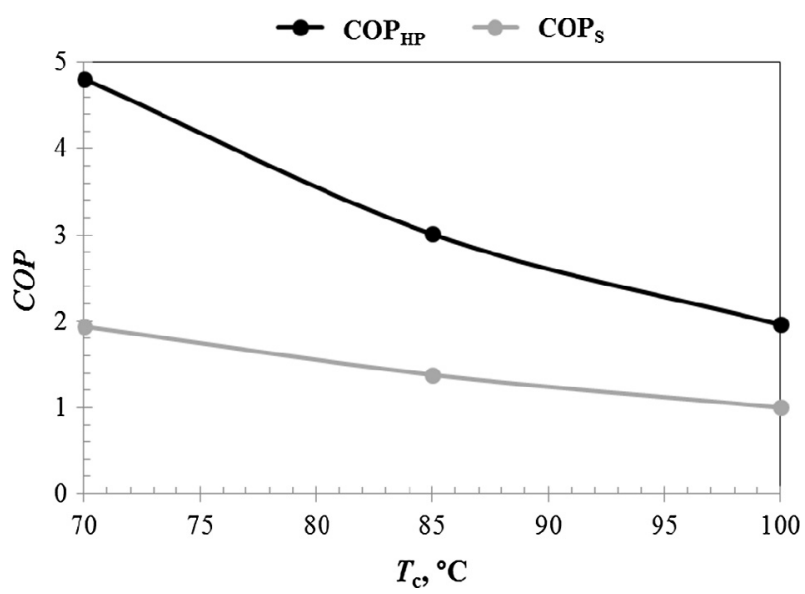

Fig. 23. Effect of charging temperature on (a) $C O P_{H P}$ and (b) $C O P_{S}$. 
for $T_{c}=85^{\circ} \mathrm{C}$ where $\mathrm{HP}$ output temperature was assumed as $55^{\circ} \mathrm{C}$ and air temperature boost of $\Delta T=30^{\circ} \mathrm{C}\left(55 \rightarrow 85^{\circ} \mathrm{C}\right)$ with the auxiliary EH were considered. The increasing $m_{a}$ in the range of $0.012 \rightarrow 0.021 \mathrm{~kg} / \mathrm{s}$ results in a rise of both $W_{o, c, \text { ave }}$ and $W_{i, c, \text { ave }}$ in the range of $0.44 \rightarrow$ $0.78 \mathrm{~kW}$ and $1.02 \rightarrow 1.16 \mathrm{~kW}$ respectively. On the other hand $W_{o, d \text {,ave }}$ and $W_{i, d \text {,ave }}$ were found as $1.68 \mathrm{KW}$ and $0.15 \mathrm{~kW}$ for all $m_{a}$ values. $C O P_{H P}$ varies between $2.06 \rightarrow 5.36$. $C O P_{s}$, which represents the ratio of $E_{o, t}$ to $E_{i, t}$ was found in close approximation for all $m_{a}$ values and was in the range of $1.48 \rightarrow 1.38$ (see Fig. 24) indicating that $m_{a}$ does not have any major impact on system overall performance.

\subsection{Parametric sensitivity analysis}

Sensitivity analysis is a crucial part of the simulation models and numerical analysis. The parameters, calculated values and variables in the model are susceptible to different uncertainty sources. For that reason, investigation of the model output parameters sensitivity to the input variables' disturbances is important [49-51].

In this analysis, the derivative of the output variables to input parameters are investigated to determine the sensitivity of the $C O P_{H P}$ and $C O P_{S}$ output variables to the effective input parameters of the $I, T_{i, c}$ $T_{c}, T_{i, d}$ and $m_{a}$ A positive value of the sensitivity reveals an increase in the objective function due to the enhancement of the input parameters; and a negative value represents a reduction in the objective function caused by increasing the input parameters [52]. Table 5 indicates the results of the sensitivity analysis. According to the analysis results, solar energy input has a major impact both on $C O P_{H P}$ and $C O P_{S}$ and increases in solar radiation provides a considerable increase in both parameters. Increases in air mass flow rate $\left(m_{a}\right)$ allows a substantial increase in $C O P_{H P}$ whilst interestingly reducing the $C O P_{S}$, however, as can be seen from table, the absolute impact of $m_{a}$ on $C O P_{S}$ compared to $C O P_{H P}$ is much lower. The only parameter that enhances both $C O P_{H P}$ and $C O P_{S}$ is the charging system inlet temperature, $T_{i, c}$. However the absolute impact of $T_{i, c}$ on both COP's is much lower when compared to the impact of $I$ and $m_{a}$. Increases in applied charging temperature $\left(T_{c}\right)$ reduce $C O P_{H P}$ and $C O P_{\mathrm{S}}$ as expected. However it is surprising that its impact is not significant. Therefore utilizing very high temperatures for moisture desorption does not provide any considerable savings on overall system performance and temperatures in the range of $80-90{ }^{\circ} \mathrm{C}$ were found to be optimal. Finally the sensitivity analysis on the discharging system inlet temperature $\left(T_{i, d}\right)$ demonstrated that, a higher $T_{i, d}$ enhances $C O P_{S}$ but reduces $C O P_{H P}$. Therefore in climates where ambient temperature is very low, part of the discharging outlet air could be recovered to preheat the incoming air to achieve a higher $C O P_{S}$.

\subsection{Validation of numerical results}

The numerical results obtained using the mathematical model presented in Section 4 were validated using the experimental data obtained from the prototype testing rig (see Section 3) as presented in Figs. 25 and 26. The numerical and experimental temperature variations of the air at the reactor outlet in the discharging cycle are given in Fig. 25. Based on the simulation results, air temperature varied in the range of $39.4 \rightarrow 29.2^{\circ} \mathrm{C}$. The numerical data was compared with 5 different experimental cycles having process durations in the range of $300 \rightarrow$ $600 \mathrm{~min}$. Despite the small differences in obtained peak temperatures, all cycles have similar profiles and they are in close approximation with the numerical data.

Numerically and experimentally obtained $C O P_{H P}$ and $C O P_{S}$ values are comparatively presented in Fig. 26a and b respectively. As seen from Fig. 26a, $C O P_{H P}$ varied in the range of $3.01 \rightarrow 4.81$ whilst the experimentally obtained $C O P_{H P \text {, ave }}$ values were between $3.11 \rightarrow 5.71$. Although the experimental results were slightly higher than the numerical data, it was found that in general they are in close approximation. A similar approach is applied to compare the numerical and experimental $\mathrm{COP}_{s}$ (see Fig. 26b). Based on the simulation results,
$C O P_{s, a v e}$ varied in the range of $1.18 \rightarrow 1.74$ with the experimental $C O P_{s}$ values being between $1.06 \rightarrow 1.83$ showing a good agreement.

The optimal operation parameters which provide the highest $\mathrm{COP}_{s}$ were determined through the optimization of the experimental and numerical analysis results and presented in Table 6. Despite conditions close to the parameters achieved in the experimental prototype, further improvement is needed for reducing heat losses particularly in the reactor. Modifications in reactor design could provide more uniform air flow across the sorbent and enhance the systems performance. At the optimal operating conditions, a COPs $=3$ could be achieved, which represents a very efficient option for heat storage.

\subsection{Real life operation of the Heat-Store system}

The developed system could be used in buildings for energy efficient space heating. A schematic illustration of the building integrated operation of the proposed Heat-Store System is given in Fig. 27. A HP could be installed in the loft area with solar air collectors being used to preheat the air before entering the HP. A commercially available PEC (psychometric energy core) unit is used in the system. The PEC could be multipurpose, where in winter it adds water vapour to the air needed for the sorption reaction whilst in summer it could act as evaporative cooler.

In the system, the HP is used for charging the sorbent and, where needed, an auxiliary heater could be installed to boost the charging air temperature before entering the sorption reactor. Current domestic attic HPs can increase air temperature by up to $60^{\circ} \mathrm{C}$. According to the obtained data in the experimental and numerical analyses SIM-3a could be charged at $\sim 85^{\circ} \mathrm{C}$. Therefore, using a small in-line duct resistance heater at the HP outlet could be beneficial to efficiently regenerate the sorbent. The HP and electrical heater are powered with electricity generated via PV panels. Alternatively, they could be powered using off-peak electric tariffs at night time.

In the charging cycle, as can be seen from Fig. 27, air is pre-heated by solar collectors then further heated in the HP condenser. Hot air passes through the sorption reactor and desorbs moisture from the sorbent. The moist exhaust air initially passes through a wall mounted air-to-air heat recovery unit to heat the incoming ventilation air. Precooled process air then enters the HP evaporator and transfers the rest of the waste heat to the refrigerant. This significantly increases the $C O P_{H P}$ as the compressor work is minimal as a result of the heat input in the evaporator.

In discharging cycle, ambient air is humidified in the PEC and passes through the sorption reactor where moisture is adsorbed and sorption heat is generated. The generated hot/dry air is then supplied to the building via ducting for space heating. The charging and discharging cycles are described below with the assigned flow numbers given in

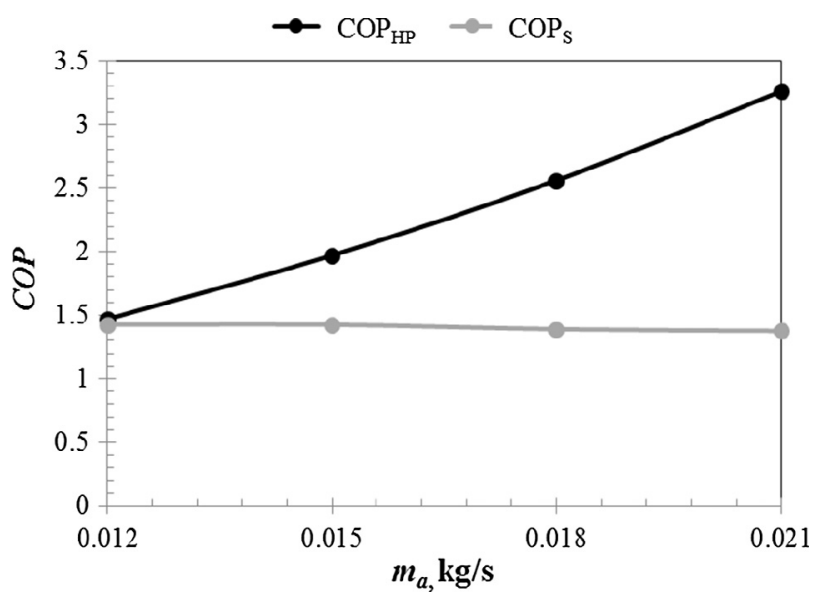

Fig. 24. Effect of air mass flow rate on (a) $C O P_{H P}$ and (b) $C O P_{S}$ for $T_{c}=85^{\circ} \mathrm{C}$. 
Table 5

Parameter sensitivity analysis results.

\begin{tabular}{|c|c|c|c|c|c|c|c|c|}
\hline$I\left(\mathrm{~kW} / \mathrm{m}^{2}\right)$ & $\frac{\partial C O P_{H P}}{\partial I}$ & $\frac{\partial C O P_{S}}{\partial I}$ & $T_{c}\left({ }^{\circ} \mathrm{C}\right)$ & $\frac{\partial C O P_{H P}}{\partial T_{\mathcal{C}}}$ & $\frac{\partial C O P_{S}}{\partial T_{\mathcal{C}}}$ & $T_{i, c}\left({ }^{\circ} \mathrm{C}\right)$ & $\frac{\partial C O P_{H P}}{\partial T_{i, c}}$ & $\frac{\partial C O P_{S}}{\partial T_{i, c}}$ \\
\hline 0.1 & 2.0511 & 4.4397 & 70 & -0.1403 & -0.0433 & 10 & 0.0247 & 0.0397 \\
\hline 0.2 & 5.3651 & 6.7237 & 85 & -0.0893 & -0.0313 & 20 & 0.0607 & 0.0457 \\
\hline 0.3 & 8.6791 & 9.0077 & 100 & -0.0383 & -0.0193 & 30 & 0.0967 & 0.0517 \\
\hline 0.4 & 11.9931 & 11.2917 & & & & 40 & 0.1327 & 0.0577 \\
\hline$T_{i, d}\left({ }^{\circ} \mathrm{C}\right)$ & $\frac{\partial C O P_{H P}}{\partial T_{i, d}}$ & $\frac{\partial C O P_{S}}{\partial T_{i, d}}$ & $m_{a}(\mathrm{~kg} / \mathrm{s})$ & $\frac{\partial C O P_{H P}}{\partial m_{a}}$ & $\frac{\partial C O P_{S}}{\partial m_{a}}$ & & & \\
\hline 10 & -0.0771 & 0.0744 & 0.012 & 148.6674 & -2.85186 & & & \\
\hline 15 & -0.0821 & 0.0624 & 0.015 & 182.001 & -5.0367 & & & \\
\hline 20 & -0.0871 & 0.0504 & 0.018 & 215.3346 & -7.22154 & & & \\
\hline 25 & -0.0921 & 0.0384 & 0.021 & 248.6682 & -9.40638 & & & \\
\hline
\end{tabular}

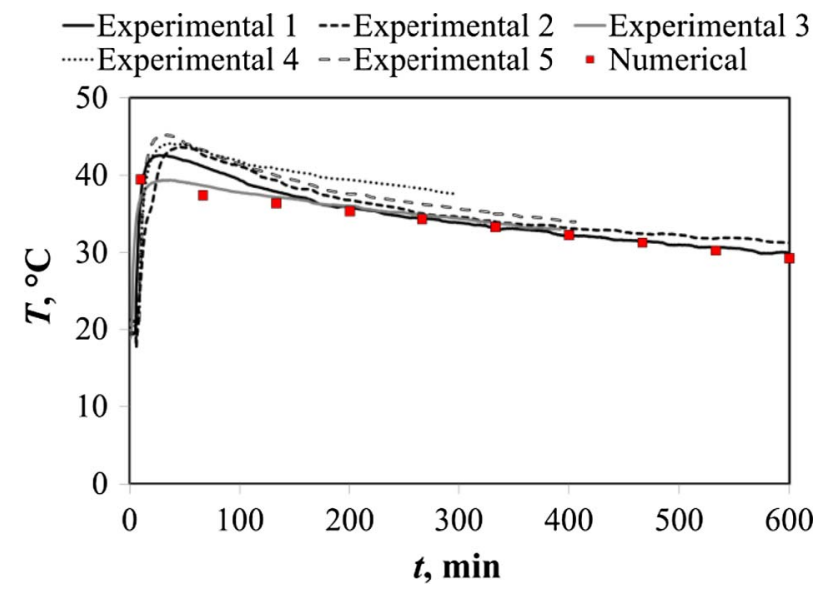

Fig. 25. Numerical and experimental air temperature variation during discharging cycle.

Fig.27.

Sorption heat storage charging:

- $1 \rightarrow 2 \rightarrow 3 \rightarrow 10 \rightarrow 4 \rightarrow 5 \rightarrow 6$ (Charging primary air stream),

- $7 \rightarrow 8 \rightarrow 12$ (Charging secondary/product air stream).

Sorption heat storage discharging

- $9 \rightarrow 10 \rightarrow 3 \rightarrow 11 \rightarrow 8 \rightarrow 12$ (Discharging air stream).

Indirect evaporative cooling line

- $9 \rightarrow 4 \rightarrow 5 \rightarrow 6$ (Indirect evaporative cooling primary/working air stream),

- $7 \rightarrow 8 \rightarrow 12$ (Indirect evaporative cooling secondary/product air stream).
Table 6

Optimal operation parameters of the Heat-Store system.

\begin{tabular}{llll}
\hline Charging & & & \\
\hline Flow number & Description & $T\left({ }^{\circ} \mathrm{C}\right)$ & $R H(\%)$ \\
\hline 1 & System inlet & 23 & 41 \\
2 & HP condenser outlet & 55 & 8 \\
3 & EH outlet - reactor inlet & 82 & 3 \\
4 & Reactor outlet - HEX inlet & 56 & 40 \\
5 & HEX outlet - HP evaporator inlet & 40 & 84 \\
6 & HP evaporator outlet- exhaust & 20 & 100 \\
7 & HEX inlet (secondary air flow) & 15 & 25 \\
8 & HEX outlet (secondary air flow) & 38 & 8 \\
Discharging & & & \\
Flow number & Description & $T\left({ }^{\circ} \mathrm{C}\right)$ & $R H(\%)$ \\
9 & System inlet & 20 & 40 \\
10 & Humidifier outlet & 17 & 80 \\
11 & Reactor outlet & 42 & 2 \\
Mass flow rate & & & \\
Charging & $m_{a, c}(\mathrm{~kg} / \mathrm{s})$ & 0.02 & \\
Discharging & $m_{a, d}(\mathrm{~kg} / \mathrm{s})$ & 0.02 & \\
\hline
\end{tabular}

Heat pump technology is one of the most sustainable and efficient ways of household space or water heating. However, their performance is strongly dependent on the ambient conditions $(T \& R H)$. The $C O P$ value of the HP dramatically drops with reducing ambient temperature. Several methods have been investigated to improve HP performance such as incorporating ground energy or solar energy [53]. In addition, there are several studies coupling SHS or LHS with HPs [54]. Benefitting from HS is vital because it can store the solar energy until the heat demand increases. By recovering stored solar energy, a HP can operate efficiently even in extremely low ambient temperatures. However, the main difficulty with using LHS lies in controlling the phase change process. Use of SHS is encumbered by the relatively low heat storage density requiring a high space requirement. Additionally, in both SHS and LHS methods, heat loss is a problem and in most cases stored heat is

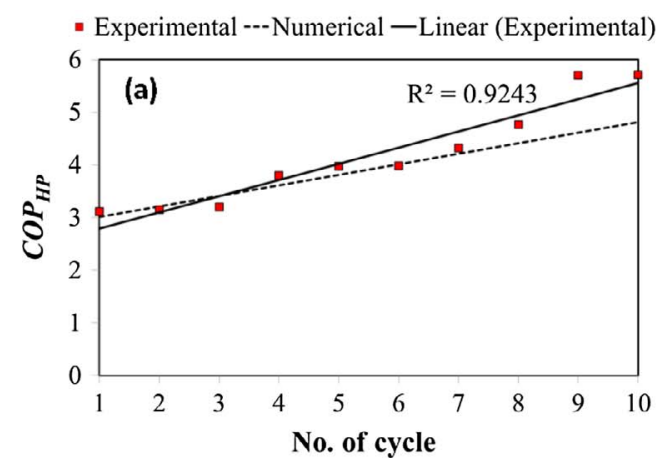

Fig. 26. Numerical and experimental (a) $C O P_{H P}$ and (b) $C O P_{s}$ values in different cycles.

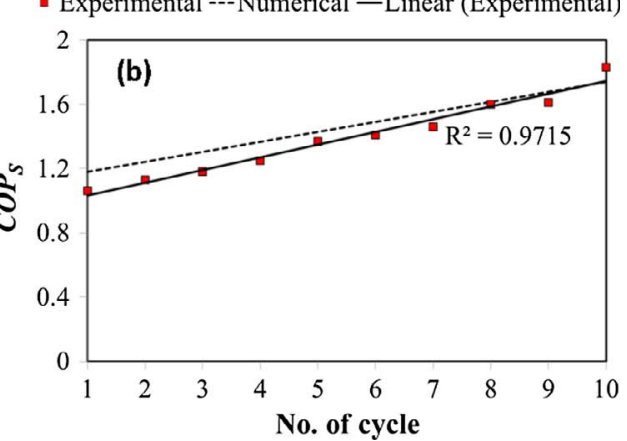




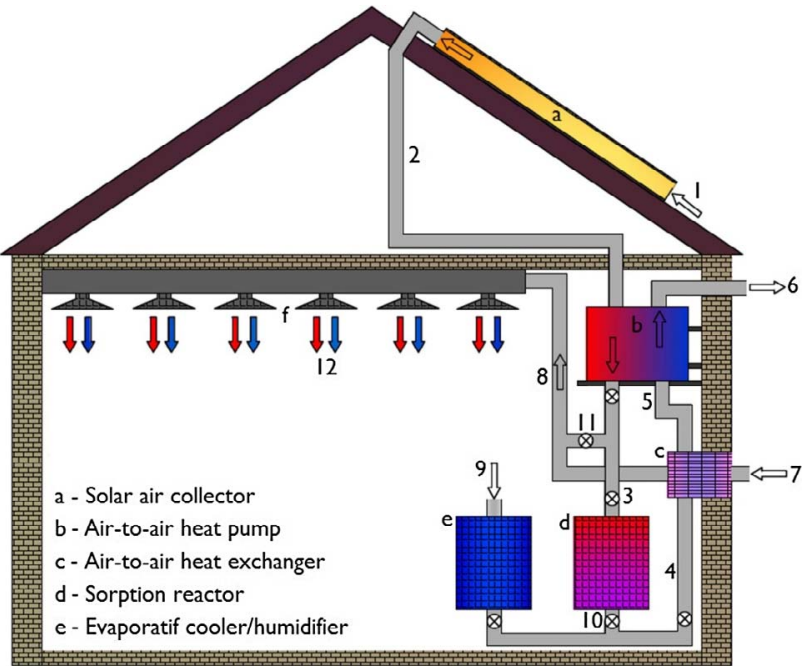

Fig. 27. Schematic illustration of the building integrated operation of Heat-Store system.

required to be consumed in a short period of time. As demonstrated in this study, THS materials have several promising aspects. The main disadvantage of this method is the high temperature requirement for desorbing the moisture in charging cycle. The conventional sorbents Zeolite $13 \mathrm{X}$ and Silica gel have been widely researched however, the high regeneration temperature $\left(>150^{\circ} \mathrm{C}\right)$ requirement is the main drawback of these materials. As presented in Section 4, salt based composite sorbents (e.g. SIMs) can provide a competitive heat output with zeolites and higher than Silica gel whilst being able to be regenerated at significantly lower temperatures. In particular, SIM-3a provided a high performance with $E_{d}>150 \mathrm{kWh} / \mathrm{m}^{3}$ at $T_{c}$ of $\sim 85^{\circ} \mathrm{C}$.

The key element that differentiates THS is the fact that mass (moisture) transfer occurs during the charging-discharging processes whilst this is not an issue in other HS methods. In the discharging process, ambient moisture is used, and if needed, the humidity of air could be boosted with evaporative or ultrasonic methods with a little energy input.

In the charging process, although the heated dry input air (e.g. $85^{\circ} \mathrm{C}$ ) spends its energy for desorbing/evaporating the water from the sorbent, the evaporated warm water (water vapour) leaves the system with the input air. Therefore, in the charging process, input thermal power with the hot-dry air and the output thermal power with the moist-warm air are in close approximation. According to the experimental data obtained with the testing rig (see: Section 4), the average inlet conditions of the air to the reactor was $T=\sim 85^{\circ} \mathrm{C}$ and $R H=$ $\sim 3 \%$, corresponding to $114 \mathrm{~kJ} / \mathrm{kg}_{\text {air }}$ and the outlet conditions of the air was $T=\sim 55^{\circ} \mathrm{C}$ and $R H=18 \%$, corresponding to $102 \mathrm{~kJ} / \mathrm{kg}_{\text {air. }}$. This condition indicates the high heat recovery potential of moist-warm exhaust air with the use of an HP system as demonstrated within the study.

As the majority of heat supplied in the charging process is recovered, the overall amount of useful heat output in a full cycle (charging + discharging) is found to be $\approx 2.4$ times greater than the electric work input to the system corresponding to a COPs $=2.4$. The efficiencies obtained with different storage methods in the literature are presented in Table 7. As seen in the table efficiencies are $<1$ in all previous studies. It should be noted that the obtained efficiencies for previous studies are thermal-to-thermal conversions whereas the present study is for electric-to-thermal conversion.

In the UK, off-peak and standard tariff electricity rates are $\approx 7 \mathrm{p} /$ $\mathrm{kWh}$ and $\approx 14 \mathrm{p} / \mathrm{kWh}$ respectively. The developed system has the advantage of being able to be charged using off peak electricity which is not the case for HPs or direct electric heaters (DEH) that are not integrated with any heat storage. The unit costs of heat production with the developed system, HP $\left(C O P_{\text {heating }}=2.5\right)$ and DEH $(\eta=1)$ were found to be $2.9 \mathrm{p} / \mathrm{kWh}_{\mathrm{t}}, 5.6 \mathrm{p} / \mathrm{kWh}_{\mathrm{t}}$ and $14 \mathrm{p} / \mathrm{kWh}_{\mathrm{t}}$, indicating that HeatStore system could provide $\sim 50 \%$ and $\sim 80 \%$ cost savings comparing to the stand alone HP and DEH systems respectively.

\section{Conclusion}

In this study a novel heat pump driven sorption storage system was numerically and experimentally investigated. In addition, new composite sorption materials were developed, characterized and experimentally tested in the novel sorption reactor.

$C O P_{s}$ varied in the range of $1 \rightarrow 2.4$ depending on sorption material properties and system operating conditions. Both the numerical and experimental results showed that, increasing charging temperature, $T_{c}$ reduces $\mathrm{COP}_{S}$. Therefore, further development of sorption materials that can be regenerated at low temperature ranges (i.e. $<70^{\circ} \mathrm{C}$ ) is crucial. That condition will enable the use of a HP without the need for an auxiliary electrical heater and could substantially increase $C O P_{S}$.

Studies on the material characterization show that Zeolite $13 \mathrm{X}$ and SIM-3m had low energy densities, $E_{d}$ at $T_{c}$ of $85^{\circ} \mathrm{C}$ which is also validated with the experimental and numerical analyses. $\mathrm{LiCl}$ demonstrated a potential benefit for improving both energy density and sorption kinetics. It is found that modifying $\mathrm{CaCl}_{2}$ and $\mathrm{MgCl}_{2}$ with $\mathrm{LiCl}$ enhances the heat output in the discharging cycle whilst enhancing the moisture removal rate in charging cycle.

According to experimental results SIM-3a and SIM-3cl were found to be the two most promising candidates among the five tested materials. Due to its better known hygrothermal and cyclic characteristics, SIM-3a was used in the experimental parametric investigations on overall system performance. Within these tests, it was found that $b=25 \mathrm{~mm}$ and $m_{a}=0.02 \mathrm{~kg} / \mathrm{s}$ are the optimal operating parameters for the developed prototype. Long cycle tests performed under these operating conditions showed that a $V s=0.04 \mathrm{~m}^{3}$ could provide $\approx 6.8 \mathrm{kWh} E_{o, d}$ for $\Delta T$ in the range of $28 \rightarrow 10^{\circ} \mathrm{C}$ over $1200 \mathrm{~min}$, corresponding to $E_{d}=170 \mathrm{kWh}$.

The outcomes obtained with the full domestic scale prototype system are promising, especially where the system could electrically driven by PV panels (e.g. day time) during the charging period. The main benefit of the developed process is to significantly reduce the peak power required for charging the material thereby being suitable to be coupled with PV panels. For instance, considering a single electrical heater used for charging the material, the required power exceeds $1 \mathrm{~kW}$ for the same air flow rate $(0.02 \mathrm{~kg} / \mathrm{s})$. In this case assuming $\eta_{P V}=10 \%$ and $I=1000 \mathrm{~W} / \mathrm{m}^{2}$, the required $\mathrm{PV}$ area would be $\approx 10 \mathrm{~m}^{2}$. In the developed system, the total required power was lower than $0.45 \mathrm{~kW}$ for charging the material as the majority of the wasted heat was recovered

\section{Table 7}

Summary of the obtained efficiencies with different heat storage methods in the literature.

\begin{tabular}{|c|c|c|c|c|}
\hline Reference & $\begin{array}{l}\text { Type of } \\
\text { study }\end{array}$ & Material & $\begin{array}{l}\text { Heat storage } \\
\text { method }\end{array}$ & $\eta_{I}$ \\
\hline [55] & Num. & Ethylene glycol & SHS & 0.8 \\
\hline$[56]$ & Exp & Water & SHS & 0.76 \\
\hline [57] & Exp. & $\mathrm{CaCl}_{2} \cdot 6 \mathrm{H}_{2} \mathrm{O}$ & LHS & 0.45 \\
\hline [58] & Exp. & Paraffin & LHS & 0.4 \\
\hline [59] & Exp. & Paraffin & LHS & 0.42 \\
\hline [53] & Exp. & Paraffin & LHS & $0.62-0.74$ \\
\hline$[60]$ & Num. & Paraffin & LHS & 0.72 \\
\hline \multirow[t]{2}{*}[23]{} & Exp & $\mathrm{SrBr}_{2}$ (Closed cycle) & THS & 0.5 \\
\hline & Exp. & Zeolite (Open cycle) & THS & 0.69 \\
\hline [27] & Exp & Zeolite & THS & $0.34-0.54$ \\
\hline \multirow[t]{2}{*}{ [61] } & Exp. & WSS $+22.4 \mathrm{wt} \% \mathrm{CaCl}_{2}$ & THS & $0.36-0.74$ \\
\hline & Exp. & $\begin{array}{l}\text { WSS }+9.6 \mathrm{wt} \% \text { lithium } \\
\text { chloride }(\mathrm{LiCl})\end{array}$ & THS & $0.4-0.66$ \\
\hline \multirow[t]{2}{*}{ [42] } & Exp. & Vermiculite- $\mathrm{CaCl}_{2}$ & THS & $0.61-0.69$ \\
\hline & Exp. & Zeolite $13 \mathrm{X}$ & THS & $0.48-0.72$ \\
\hline Present study & Exp. & Vermiculite- $\mathrm{CaCl}_{2}$ & THS & 2.4 \\
\hline
\end{tabular}


with a resultant PV area $<4.5 \mathrm{~m}^{2}$.

Considering that one of the highest consumers of energy in the building sector is for space heating, converting and storing the electricity generated via PV panels as thermal energy with minimal thermal losses could be a promising option that will enhance the utility of PV technology whilst reducing the costs for energy storage.

\section{Acknowledgements}

The authors wish to gratefully acknowledge the support of Innovate UK (United Kingdom) for funding the research presented in this paper (Project reference: 131926, 'Innovative Energy Saving Sorption-Storage Heater').

\section{References}

[1] The European Parliament and the Council of the EU. Directive 2010/31/EU of the European parliament and of the council of 19 May 2010 on the energy performance of buildings (recast). Official Journal of the European Communities 2010;L153:13-35.

[2] Desideri U, Arcioni L, Leonardi D, Cesaretti L, Perugini P, Agabitini E, Evangelisti N. Design of a multipurpose "zero energy consumption" building according to European directive 2010/31/EU: architectural and technical plants solutions. Energy 2013;58:157-67.

[3] Alva G, Liu L, Huang X, Fang G. Thermal energy storage materials and systems for solar energy applications. Renew Sustain Energy Rev 2017;68:693-706.

[4] Gondre D, Johannes K, Kuznik F. Specification requirements for inter-seasonal heat storage systems in a low energy residential house. Energy Convers Manage 2014;77:628-36.

[5] Zhang X, Li M, Shi W, Wang B, Li X. Experimental investigation on charging and discharging performance of absorption thermal energy storage system. Energy Convers Manage 2014;85:425-34.

[6] Herrando M, Markides CN. Hybrid PV and solar-thermal systems for domestic heat and power provision in the UK: techno-economic considerations. Appl Energy 2016;161:512-32.

[7] Carboncommentary. Domestic batteries to store excess PV and reduce peak demand loads [Online]. 2014. Available: < http://www.carboncommentary.com/blog/ 2014/10/17/domestic-batteries-to-store-excess-pv-and-reduce-peak-demandloads $>$ [Accessed 15.05.2016].

[8] UKPower. Economy 7 Tariffs [Online]. 2016. Available < http://www.ukpower.co. $\mathrm{uk} /$ home_energy/economy-7 $>$ [Accessed 10.03.2016].

[9] UKPower. Economy 10 electricity heating tariff [Online]. 2016. Available < http:// www.ukpower.co.uk/home energy/economy $10>$ [Accessed 10.03.2016].

[10] Aydin D, Casey SP, Riffat S. The latest advancements on thermochemical heat storage systems. Renew Sustain Energy Rev 2015;41:356-67.

[11] Hongois S, et al. Development and characterisation of a new $\mathrm{MgSO}_{4}$-zeolite composite for long-term thermal energy storage. Sol Energy Mater Sol Cells 2011;95(7):1831-7.

[12] Jänchen J, et al. Studies of the water adsorption on Zeolites and modified mesoporous materials for seasonal storage of solar heat. Sol Energy 2004;76(1-3):339-44.

[13] Jänchen J, et al. Calorimetric investigation on zeolites, $\mathrm{AlPO}_{4}$ 's and $\mathrm{CaCl}_{2}$ impregnated attapulgite for thermochemical storage of heat. Thermochim Acta 2005;434(1-2):37-41.

[14] Jänchen J, Stach H. Adsorption properties of porous materials for solar thermal energy storage and heat pump applications. Energy Procedia 2012;30:289-93.

[15] Aristov YI. Novel materials for adsorptive heat pumping and storage: screening and nanotailoring of sorption properties. J Chem Eng Jpn 2007;40(13):1242-51.

[16] Ponomarenko I, Glaznev I, Gubar A, Aristov YI, Kirik S. Synthesis and water sorption properties of a new composite $\mathrm{CaCl}_{2}$ confined into SBA-15 pores. Microporous Mesoporous Materials 2010;129(1):243-50.

[17] Molenda $\mathrm{M}$, et al. Reversible hydration behavior of $\mathrm{CaCl}_{2}$ at high $\mathrm{H}_{2} \mathrm{O}$ partial pressures for thermochemical energy storage. Thermochim Acta 2013;560:76-81.

[18] Gordeeva L, Aristov YI. Composites 'salt inside porous matrix' for adsorption heat transformation: a current state-of-the-art and new trends. Int J Low Carbon Technol 2012;7(4):288-302.

[19] Korhammer K, et al. Sorption and thermal characterization of composite materials based on chlorides for thermal energy storage. Appl Energy 2016;162:1462-72.

[20] Jiang L, et al. Investigation on performance of multi-salt composite sorbents for multilevel sorption thermal energy storage. Appl Energy 2017;190:1029-38.

[21] Lizana J, et al. Advances in thermal energy storage materials and their applications towards zero energy buildings: a critical review. Appl Energy 2017;203:219-39.

[22] Courbon E. A new composite sorbent based on $\mathrm{SrBr}_{2}$ and silica gel for solar energy storage application with high energy storage density and stability. Appl Energy 2017;190:1184-94.

[23] Abedin AH, Rosen MA. Closed and open thermochemical energy storage: energyand exergy-based comparisons. Energy 2012;41(1):83-92

[24] Mette B, et al. New highly efficient regeneration process for thermochemical energy storage. Appl Energy 2013;109:352-9.

[25] Mette B, Kerskes H, Drück H. Experimental and numerical investigations of different reactor concepts for thermochemical energy storage. Energy Procedia
2014;57:2380-9.

[26] Zondag $\mathrm{H}$, et al. Prototype thermochemical heat storage with open reactor system. Appl Energy 2013;109:360-5.

[27] Johannes K, et al. Design and characterisation of a high powered energy dense zeolite thermal energy storage system for buildings. Appl Energy 2015;159:80-6.

[28] Tatsidjodoung P, et al. Experimental and numerical investigations of a zeolite 13X/ water reactor for solar heat storage in buildings. Energy Convers Manage 2016;108:488-500.

[29] Michel B, Mazet N, Neveu P. Experimental investigation of an innovative thermochemical process operating with a hydrate salt and moist air for thermal storage of solar energy: global performance. Appl Energy 2014;129:177-86.

[30] Zettl B, Englmair G, Steinmaurer G. Development of a revolving drum reactor for open-sorption heat storage processes. Appl Therm Eng 2014;70:42-9.

[31] Liu H, et al. Honeycomb filters made from mesoporous composite material for an open sorption thermal energy storage system to store low-temperature industrial waste heat. Int J Heat Mass Transf 2013;65:471-80.

[32] Finck C, et al. Quantifying demand flexibility of power-to-heat and thermal energy storage in the control of building heating systems. Appl Energy 2017. http://dx.doi. org/10.1016/j.apenergy.2017.11.036. In Press.

[33] Li TX, et al. A novel solid-gas thermochemical multilevel sorption thermal battery for cascaded solar thermal energy storage. Appl Energy 2010;161:1-10.

[34] Donkers PAJ, et al. A review of salt hydrates for seasonal heat storage in domestic applications. Appl Energy 2017;199:45-68.

[35] Lele AF, et al. Thermal decomposition kinetic of salt hydrates for heat storage systems. Appl Energy 2015;154:447-58.

[36] Scapino L, et al. Sorption heat storage for long-term low-temperature applications: a review on the advancements at material and prototype scale. Appl Energy 2017;190:920-48.

[37] Fumey B, Weber R, Baldini L. Liquid sorption heat storage - a proof of concept based on lab measurements with a novel spiral fined heat and mass exchanger design. Appl Energy 2017;200:215-25.

[38] Jiang L, et al. Analysis on innovative modular sorption and resorption thermal cell for cold and heat cogeneration. Appl Energy 2017;204:767-79.

[39] Ströhle S, et al. Upgrading sensible-heat storage with a thermochemical storage section operated at variable pressure: an effective way toward active control of the heat-transfer fluid outflow temperature. Appl Energy 2017;196:51-61.

[40] Casey SP, et al. Salt impregnated desiccant matrices for 'open' thermochemical energy storage-selection, synthesis and characterization of candidate materials. Energy Build 2014;84:412-25.

[41] Casey SP, Aydin D, Riffat S, Elvins J. Salt impregnated desiccant matrices for 'open' thermochemical energy storage-hygrothermal cyclic behaviour and energetic analysis by physical experimentation. Energy Build 2015;92:128-39.

[42] Aydin D, Casey SP, Chen X, Riffat S. Novel 'open-sorption pipe' reactor for solar thermal energy storage. Energy Convers Manage 2016;121:321-34.

[43] Casey SP, Aydin D, Chen X, Riffat S. Salt impregnated desiccant matrices for 'open' thermochemical energy conversion and storage-improving energy density through hygrodynamic \& thermodynamic reactor design. Energy Convers Manage 2017;142:426-40.

[44] Cengel YA, Boles MA. Thermodynamics: an engineering approach. 2006. McGrawHill, 5th ed. ISBN: 0072884959 .

[45] Sensirion, the sensor company. < https://www.sensirion.com/fileadmin/user upload/customers/sensirion/Dokumente/Humidity_Sensors/Sensirion_Humidity_ Sensors_Introduction_to_Relative_Humidity_V2.pdf > [Accessed on 5.10.2016].

[46] Aydin D, Casey SP, Riffat S. Numerical analysis of solar assisted seasonal 'open' thermochemical heat storage. Int J Low Carbon Technol 2015;10(2):131-8.

[47] Marias F, Neveu P, Tanguy G, Papillon P. Thermodynamic analysis and experimental study of solid/gas reactor operating in open mode. Energy 2014;66:757-65.

[48] Buker MS, Mempouo B, Riffat SB. Performance evaluation and techno-economic analysis of a novel building integrated PV/T roof collector: an experimental validation. Energy Build 2014;76:164-75.

[49] Shirvan M, et al. Numerical simulation and sensitivity analysis of effective parameters on natural convection and entropy generation in a wavy surface cavity filled with a nanofluid using RSM. Numer Heat Transf Part A Appl 2017;70(10):1157-77.

[50] Mamourian M, et al. Vortex generators position effect on heat transfer and nanofluid homogeneity: a numerical investigation and sensitivity analysis. Appl Therm Eng 2016;107:123-47.

[51] Shirvan M, et al. Numerical simulation and sensitivity analysis of effective parameters on heat transfer and homogeneity of $\mathrm{Al}_{2} \mathrm{O}_{3}$ nanofluid in a channel using DPM and RSM. Adv Powder Technol 2016;27(5):1980-91.

[52] Shirvan M, et al. Numerical investigation and sensitivity analysis of effective parameters to obtain potential maximum power output: a case study on Zanjan prototype solar chimney power plant. Energy Convers Manage 2017;136:350-60.

[53] Utlu Z, Aydin D, Kincay O. Comprehensive thermodynamic analysis of a renewable energy sourced hybrid heating system combined with latent heat storage. Energy Convers Manage 2014;84:311-25.

[54] Aydin D, Utlu Z, Kincay O. Thermal performance analysis of a solar energy sourced latent heat storage. Renew Sustain Energy Rev 2015;50:1213-25.

[55] Hussain M, Dincer I, Zubair S. A feasibility study of using thermal energy storage in a conventional air-conditioning system. Int J Energy Res 2004;28:955-67.

[56] Wang $\mathrm{H}$, et al. A case study of underground thermal storage in a solar-ground coupled heat pump system for residential buildings. Renew Energy 2009;34:307-14.

[57] Koca A, et al. Energy and exergy analysis of a latent heat storage system with phase change material for a solar collector. Renew Energy 2008;33:567-74.

[58] Öztürk HH. Experimental evaluation of energy and exergy efficiency of a seasonal latent heat storage system for greenhouse heating. Energy Convers Manage 
2005;46:1523-42.

[59] Başcetinçelik A, Paksoy H, Demirel Y. Energetic and exergetic efficiency of latent heat storage system for greenhouse heating. Renew Energy 1999;16:691-4.

[60] Xu B, Li P, Chan CL. Energy Storage Start-up strategies for concentrated solar power plants with a dual-media thermal storage system. J Sol Energy Eng
2015;137(5):051002-051002-12. doi:1 0.1115/1.4030851.

[61] Liu H, Nagano K, Togawa J. A composite material made of mesoporous siliceous shale impregnated with lithium chloride for an open sorption thermal energy storage system. Sol Energy 2015;111:186-200. 